\title{
Structural and Functional Rescue of Chronic Metabolically Stressed Optic Nerves through Respiration
}

\author{
Mohammad Harun-Or-Rashid, ${ }^{1}$ Nate Pappenhagen, ${ }^{1,2}$ Peter G. Palmer, ${ }^{1}$ Matthew A. Smith, ${ }^{1}$ Victoria Gevorgyan, ${ }^{1}$ \\ Gina N. Wilson, ${ }^{1,2}$ Samuel D. Crish, ${ }^{1}$ and ${ }^{\mathbb{D} D e n i s e}$ M. Inman ${ }^{1}$ \\ ${ }^{1}$ Northeast Ohio Medical University, Rootstown, Ohio 44272 and ${ }^{2}$ School of Biomedical Science, Kent State University, Kent, Ohio 44242
}

Axon degeneration can arise from metabolic stress, potentially a result of mitochondrial dysfunction or lack of appropriate substrate input. In this study, we investigated whether the metabolic vulnerability observed during optic neuropathy in the DBA/2J (D2) model of glaucoma is due to dysfunctional mitochondria or impaired substrate delivery to axons, the latter based on our observation of significantly decreased glucose and monocarboxylate transporters in D2 optic nerve (ON), human ON, and mice subjected to acute glaucoma injury. We placed both sexes of D2 mice destined to develop glaucoma and mice of a control strain, the DBA/2J-Gpnmb ${ }^{+}$, on a ketogenic diet to encourage mitochondrial function. Eight weeks of the diet generated mitochondria, improved energy availability by reversing monocarboxylate transporter decline, reduced glial hypertrophy, protected retinal ganglion cells and their axons from degeneration, and maintained physiological signaling to the brain. A robust antioxidant response also accompanied the response to the diet. These results suggest that energy compromise and subsequent axon degeneration in the D2 is due to low substrate availability secondary to transporter downregulation.

Key words: b-hydroxybutyrate; ketogenic diet; neural-glial interaction; optic nerve

Significance Statement

We show axons in glaucomatous optic nerve are energy depleted and exhibit chronic metabolic stress. Underlying the metabolic stress are low levels of glucose and monocarboxylate transporters that compromise axon metabolism by limiting substrate availability. Axonal metabolic decline was reversed by upregulating monocarboxylate transporters as a result of placing the animals on a ketogenic diet. Optic nerve mitochondria responded capably to the oxidative phosphorylation necessitated by the diet and showed increased number. These findings indicate that the source of metabolic challenge can occur upstream of mitochondrial dysfunction. Importantly, the intervention was successful despite the animals being on the cusp of significant glaucoma progression.

\section{Introduction}

Energy compromise contributes to axon degeneration, though it is unknown whether low energy enables the degeneration cascade or is a byproduct of the execution. ATP depletion results in axon degeneration that can be prevented by the Wallerian degeneration slow fusion protein (Wld ${ }^{\text {s; }}$ Shen et al., 2013), which includes nicotinamide mononucleotide adenylyltransferase-1 (NMNAT1). NMNAT catalyzes the ATP-dependent conversion of nicotinamide mononucleotide to nicotinamide adenine dinucleotide

Received Dec. 29, 2017; revised Feb. 27, 2018; accepted April 24, 2018.

Author contributions: M.H.-0.-R., S.D.C., and D.M.I. designed research; M.H.-O.-R., N.P., P.G.P., M.A.S., V.G., G.N.W., and D.M.I. performed research;S.D.C. contributed unpublished reagents/analytic tools; M.H.-O.-R., M.A.S., S.D.C., and D.M.I. analyzed data; M.H.-O.-R. and D.M.I. wrote the paper.

This work was supported by National Institutes of Health Grants EY-022358 (S.D.C.) and EY-026662 (D.M.I.). We thank Kayla Trautman and Amelia McMullen for excellent technical assistance.

The authors declare no competing financial interests.

Correspondence should be addressed to Denise M. Inman, Northeast Ohio Medical University, 4209 State Route 44, Rootstown, 0H 44272. E-mail: dinman@neomed.edu.

DOI:10.1523/JNEUROSCI.3652-17.2018

Copyright $\odot 2018$ the authors $\quad 0270-6474 / 18 / 385122-18 \$ 15.00 / 0$
$\left(\mathrm{NAD}^{+}\right)$, an essential cofactor in glycolysis and the Krebs cycle within mitochondria. Increased levels of $\mathrm{NAD}^{+}$, enabled by deletion of the axon destruction factor SARM1 (Gerdts et al., 2015) or exogenous application (Araki et al., 2004; Wang et al., 2005), can significantly delay axon degeneration, including of retinal ganglion cell (RGC) axons in a model of glaucoma (Williams et al., 2017). However, in some contexts, increased $\mathrm{NAD}^{+}$has failed to promote axon survival after injury (Sasaki et al., 2009). Accordingly, NMNAT without enzymatic activity can protect axons from degeneration (Zhai et al., 2006), suggesting an axon-protective function of NMNAT beyond NAD ${ }^{+}$generation (Zhai et al., 2008). Lacking an unequivocal role for NMNAT or $\mathrm{NAD}^{+}$indicates that a broader view of the role of energy and mitochondria in axon degeneration may be warranted.

Glaucoma is an optic neuropathy in which RGC bodies are maintained for a short time after the axons degenerate (Howell et al., 2007; Buckingham et al., 2008; Crish et al., 2010). This survival of RGC bodies provides a fortuitous intervention window that suggests axon protection could be a viable approach toward maintaining vision in this disease. Optic nerves (ONs) in the DBA/2J 
(D2) mouse model of glaucoma are metabolically vulnerable even before overt glaucomatous pathology (Baltan et al., 2010). Upon onset of elevated intraocular pressure (IOP), D2 optic nerves exhibited lower ATP levels (Baltan et al., 2010), increased fission (Ju et al., 2008), mitochondrial cristae loss (Coughlin et al., 2015), and reduced ratios of mitochondrial volume to RGC axon volume that develop with glaucoma progression (Kleesattel et al., 2015). A metabolic connection has also emerged from glaucoma being more prevalent in patients with diabetes, for which elevated intraocular pressure can be accompanied by elevated fasting glucose levels (Song et al., 2016). A retrospective study of individuals with diabetes who were prescribed metformin, a drug that lowers hepatic glucose production through mild, transient inhibition of complex I of the mitochondrial electron transport chain (Viollet et al., 2012), showed a significant decrease in risk for development of open angle glaucoma (Lin et al., 2015). Metformin has been termed a calorie restriction mimetic to indicate its ability to recapitulate the gene expression profile of caloric restriction (Dhahbi et al., 2005), including promotion of metabolic efficiency (Ingram et al., 2006). In contrast to caloric restriction, intermittent fasting can achieve neuroprotective effects without limiting dietary intake, a result that corresponded to significant increases in the ketone body $\beta$-hydroxybutyrate $(\beta \mathrm{HB})$ over caloric restriction (Anson et al., 2003). These data indicate that metabolic syndromes may contribute to glaucoma incidence, and amelioration may be possible through management of mitochondrial efficiency or substrate complement (ketone bodies instead of glucose). Therefore, an important adjunct to the role of mitochondrial function in the pathogenesis of glaucoma is the provision of specific substrates with which to generate ATP.

Glucose or lactate is provided to axons through astrocytes or oligodendrocytes (Saab et al., 2016) via glucose and monocarboxylate transporters (MCTs), respectively (Pierre et al., 2002; Simpson et al., 2007). While neurons and their axons can use multiple energy sources depending on availability, they prefer lactate (BouzierSore et al., 2006). Since mitochondria rely on lactate or glycolysisderived pyruvate to generate ATP, a key question is whether energy substrate availability or mitochondrial defect contributes to the energy compromise observed before axon degeneration, particularly in glaucoma. To test this, we placed mice on a ketogenic diet (KD), composed primarily of fat, that would promote mitochondrial biogenesis (Bough et al., 2006) and compel mitochondrial respiration through use of ketone bodies generated as a result of $\beta$-oxidation of fatty acids, either in the liver or the astrocytes (Guzmán and Blázquez, 2004). New mitochondria are generated from those existing, so acquired defects in mitochondrial DNA are passed on to the newly generated organelles (Ozawa, 1995; Kowald and Kirkwood, 2000). Hence, a byproduct of increased mitochondrial biogenesis may include an unmasking of mitochondrial defect.

Mitochondria are a key target of the KD (Maalouf et al., 2009). The KD resulted in a coordinated upregulation of transcripts for genes encoding metabolic proteins, including 39 mitochondrial proteins (Bough et al., 2006). A greater ATP/ADP ratio was observed in the CNS as a result of the KD, with an overall increase in cerebral energy stores (Devivo et al., 1978). Isolated mitochondria from mice on a KD generated lower levels of reactive oxygen species (ROS), most likely through decreased mitochondrial membrane potential as a result of greater uncoupling (Sullivan et al., 2004). KDs have also shown promise in ameliorating neurodegenerative disease, including Alzheimer's disease (Henderson et al., 2009; Hertz et al., 2015), Parkinson's disease (Yang and Cheng, 2010), and amyotrophic lateral sclerosis (ALS; Zhao et al.,
2006). The neuroprotective effect of the KD may derive from stimulating mitochondrial biogenesis (Bough et al., 2006) or the histone deacetylase inhibition (Shimazu et al., 2013) and antiinflammatory (Rahman et al., 2014) effects of $\beta$-hydroxybutyrate, the primary ketone body. Alternatively, the change of energy source away from glucose may upend processes in glycolytic cells that result in overall improved energy management and use. In this study, the KD was used as a tool to test whether promoting mitochondrial function would reveal a specific mitochondrial defect in glaucoma-induced axon degeneration. The KD did not reveal substantial defects in $\mathrm{ON}$ mitochondria; it reversed the observed metabolic deficits and protected retinal ganglion cell axon structure and function.

\section{Materials and Methods}

Animals. D2 (RRID:IMSR_JAX:000671), DBA/2J ${ }^{\text {wt-gpmnb }}$ (D2G; RRID: IMSR_JAX:007048), and B6.Cg-Tg(Thy1-CFP/COX8a)S2Lich/J (MitoCFP; RRID:IMSR_JAX:007967; The Jackson Laboratory) were purchased and housed at Northeast Ohio Medical University. The D2 mouse spontaneously develops pigmentary glaucoma secondary to a iris stromal atrophy and iris pigment dispersion disease as a result of mutations in the Tyrp1 and Gpnmb genes, respectively (Anderson et al., 2002). The D2G mouse shares the $\mathrm{D} 2$ genetic background but carries a wild-type allele of the Gpnmb gene; it does not develop pigmentary glaucoma. All procedures were approved by the Institutional Animal Care Committee and performed in accordance with the Association for Research in Vision and Ophthalmology Statement for the Use of Animals in Ophthalmic and Vision Research.

For the initial characterization of metabolic vulnerability (Fig. 1 and Fig. 1-1 available at https://doi.org/10.1523/JNEUROSCI.3652-17.2018. f1-1, Fig. 2 and Fig. 2-1 available at https://doi.org/10.1523/JNEUROSCI. 3652-17.2018.f2-1, Fig. 3 and Fig. 3-1 available at https://doi.org/10.1523/ JNEUROSCI.3652-17.2018.f3-1), DBA/2J mice at 10 months of age were selected for their axon transport deficit, as determined by loss of cholera toxin-B (CTB) labeling in the superior colliculus (SC). This staging of the mice ensured the analysis of mice with similar degrees of optic nerve pathology. The 3-and 6-month-old mouse age groups had no deficit in axon transport as determined by intact CTB labeling in the superior colliculus (data not shown). For the intervention experiments (Figs. 4, 5, 6,7 ), all mice were used, regardless of CTB labeling status. Subject numbers $(n)$ are either the number of eyes or optic nerves, as indicated in the figure legends.

Intraocular pressure. Intraocular pressure was measured using a TonoLab rebound tonometer calibrated for mice. Mice were anesthetized ( $2.5 \%$ isoflurane delivered by vaporizer with oxygen) while 10-20 measures were taken and averaged. The instrument-calculated running average was not used except to determine the quality of measurement as indicated by the SD bar. IOP measures were taken within 3 min of anesthetization to avoid any anesthetic-induced decline in IOP (Ding et al., 2011). IOP integrals were calculated for the mice subjected to acute glaucoma injury (see below) by subtracting the baseline IOP from the weekly, then multiplying the difference by the number of days between IOP measures. These week-by-week numbers were then summed for the IOP integral.

Anterograde tracing. Mice were anesthetized using isoflurane $(2.5 \%$ delivered by vaporizer with oxygen) and a drop of $0.5 \%$ proparacaine hydrochloride was placed on the cornea. Curved forceps were used to stabilize the proptosed eye while $1.5 \mu \mathrm{l}$ of cholera toxin-B conjugated to Alexa Fluor 488 (CTB-488; C22841, Thermo Fisher Scientific) was injected into the posterior chamber just caudal to the ora serrata using a 33 ga needle attached to a $5 \mu \mathrm{l}$ Hamilton syringe. Three days later, mice were killed with an overdose of $300 \mathrm{mg} / \mathrm{kg}$ sodium pentobarbital (Beuthanasia-D, Schering-Plough Animal Health) and perfused with 0.1 м PBS. For samples bound to mRNA or protein analysis, tissue was removed at this stage and placed in TRIzol (catalog \#15596026, Thermo Fisher Scientific) or Tissue Protein Extraction Reagent (T-PER, 78510, Thermo Fisher Scientific), respectively, and the superior colliculus was exposed and a photo- 
A

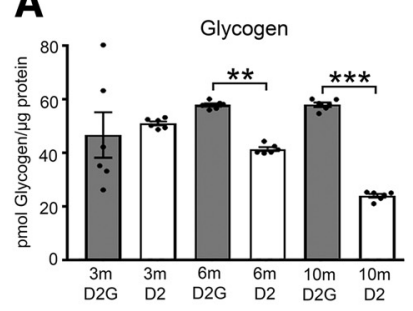

D

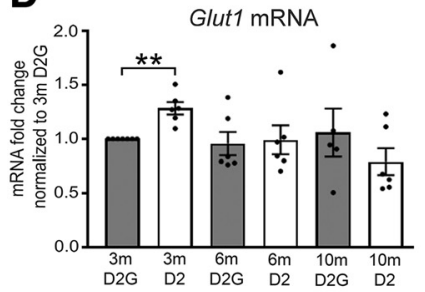

F

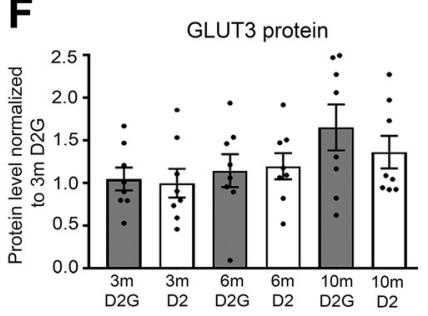

B

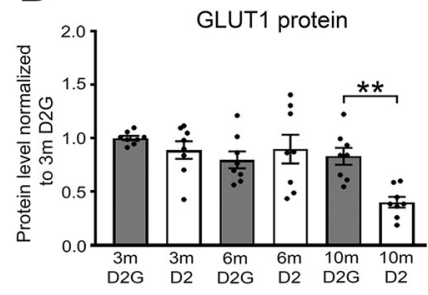

E

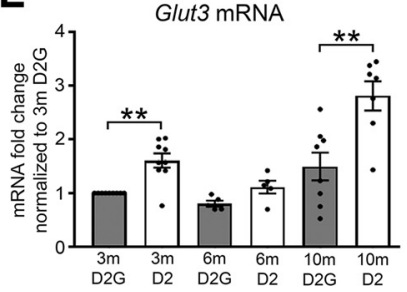

$\mathrm{H}$

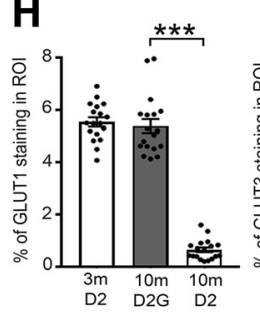

C
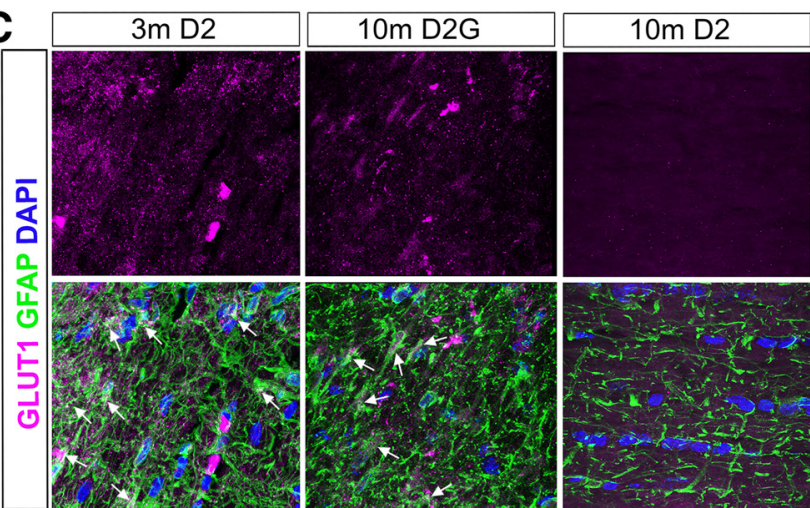

G
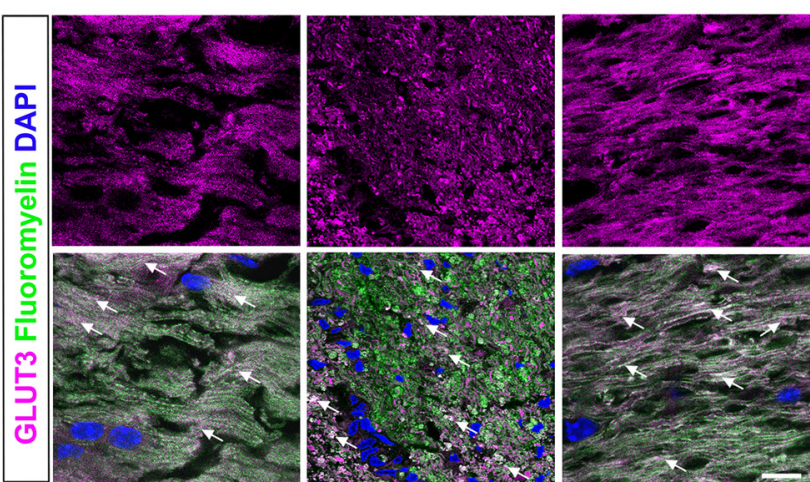

Figure 1. Glycogen and glial glucose transporters decreased with glaucoma pathology. $\boldsymbol{A}$, Glycogen analysis in 3-, 6-, and 10-month-old D2 and control D2G ONs ( $n=600 \mathrm{Ns} / \mathrm{group}) . \boldsymbol{B}, \boldsymbol{F}$, Capillary electrophoresis of GLUT1 $(\boldsymbol{B})$ and GLUT3 $(\boldsymbol{F})$ protein in 3-, 6-, and 10-month-old D2 and D2G ONs normalized to total protein then to 3-month-old D2G protein levels ( $n=80$ Ns/group). See Figure 1-1 available at https://doi.org/10.1523/JNEUROSCI.3652-17.2018.f1-1. C, Distribution of GLUT1 in ONs of 3-month-old D2 and 10-month-old D2G and D2 optic nerves immunolabeled with GFAP (green). Arrows indicate colocalization of GLUT1 and GFAP ( $n=3$ sections/ON, $n=6$ ONs/group). D, E, Glut1 and Glut3 mRNA levels in 3-, 6-, and 10-month-old D2 and D2G 0Ns, normalized to Hprt mRNA then to 3-month-old D2G mRNA ( $n=5-7$ 0Ns/group). See Figure 1-1 available at https://doi.org/10.1523/JNEUROSCI.3652-17.2018.f1-1. G, Distribution of GLUT3 in 0Ns stained with FluoroMyelin. Arrows indicate colocalization of GLUT3 with FluoroMyelin ( $n=3$ sections/ON, $n=60 \mathrm{Ns} /$ group). $\boldsymbol{H}, \boldsymbol{I}$, Percentage of mean fluorescence intensity in the ROI for GLUT1 ( $(C)$ and GLUT3 (G). All values are presented as the mean \pm SEM, using one-way ANOVA and Tukey's posthoc test. $\boldsymbol{A}, F_{(5,30)}=18.59,{ }^{* *} p=0.0022,{ }^{* * *} p=0.00011 ; \boldsymbol{B}, F_{(5,42)}=6.463,{ }^{* *} p=0.0077 ; \mathbf{D}, F_{(5,30)}=1.906$, ${ }^{* *} p=0.001 ; \boldsymbol{E}_{,} F_{(5,37)}=15.58,{ }^{* *} p=0.0023,{ }^{* *} p=0.001 ; \boldsymbol{H}, F_{(2,51)}=210.4,{ }^{* * *} p=0.0001$. Scale bar, $\boldsymbol{C}, \mathbf{G}, 20 \mu \mathrm{m}$.

micrograph taken. For tissue used for immunolabeling, mice were perfused with $4 \%$ paraformaldehyde in $0.1 \mathrm{~m}$ PBS, and tissue was removed and postfixed for $24 \mathrm{~h}$ (brain and optic nerve) or $1 \mathrm{~h}$ (eyes).

Analysis of the anterograde tracing within the superior colliculus proceeded with $50 \mu \mathrm{m}$ serial sections through the superior colliculus mounted to SuperFrost slides (Thermo Fisher Scientific) and then imaged on an AxioZoom stereomicroscope (Zeiss). An ImageJ-FIJI (Schindelin et al., 2012) macro, available by request, was used to calculate the percentage of the area of the retinorecipient portion of the superior colliculus (percentage area fraction) showing fluorescent labeling from the CTB conjugate compared with background labeling, as evident in the deep layers of superior colliculus. (Crish et al., 2010). Data are presented as the percentage area fraction.

Diets. D2 mice at 9 months of age were switched from standard lab chow [Diet 5008, Formulab (26.8\% protein, 56.4\% carbohydrate, $16.7 \%$ fat] ad libitum, to a very low carbohydrate, ketogenic diet (catalog \#D12369B) or a control diet (catalog \#D12359, Research Diets) for 8 weeks. The ketogenic diet was $10.4 \%$ protein, $0.1 \%$ carbohydrate, and $89.5 \%$ fat. The control diet was $10.4 \%$ protein, $78.2 \%$ carbohydrate, and $11.5 \%$ fat. The ketogenic diet was a soft dough, delivered to the mice in small stainless steel bowls, while the control diet was provided as pellets in the cage hopper. All mice received a nylon chew (I-Chews, Animal Specialties and Provisions) to provide a non-nutritive chewing surface, addressing the potential tooth overgrowth anticipated in mice provided the soft dough. All mice were weighed before the experiment, then once weekly over 8 weeks. Ketones from tail vein blood were measured using a Nova Max Plus hand-held ketone testing device once weekly for one to two control and ketogenic diet mice. Final measurements of plasma $\beta$-hydroxybutyrate levels were made from blood collected at the time of killing (see below).
Acute glaucoma model. Mice were anesthetized as above, and a drop of tropicamide was placed on the cornea to dilate the pupil. After pupil dilation, $0.5 \%$ proparacaine hydrochloride eyedrops (Henry Schein Animal Health) were placed on the cornea. Curved forceps were used to stabilize the proptosed eye while a glass pulled micropipette was used to inject $1.5 \mu \mathrm{l}$ of $8 \mu \mathrm{m}$ magnetic beads (catalog \#UMC4F, Bangs Laboratories) into the central anterior chamber. While the micropipette was still in place, a neodymium magnet was used to pull the beads into the iridocorneal angle to occlude the trabecular meshwork. Once distributed, the micropipette was removed, the eye covered in Pura-Lube ophthalmic ointment, and the mice allowed to recover on a warm water blanket. Two days after the bead injection, and then weekly for $4-5$ weeks, IOP was measured as above. Tissue was analyzed from mice that demonstrated at least $200 \mathrm{mmHg}$-days of IOP increase.

Optic nerve analysis. Mice given an overdose of sodium pentobarbital (300 mg/kg, Beuthanasia-D) had their eyes removed with a scalpel then the optic nerves cut from the optic chiasm after the brains were taken from the skull casing. The optic nerves were immersion fixed in $2 \%$ paraformaldehyde and $2.5 \%$ glutaraldehyde in $0.1 \mathrm{~m}$ sodium cacodylate buffer, $\mathrm{pH} 7.4$, then stained with $2 \%$ osmium (Electron Microscopy Sciences), followed by $2 \%$ potassium ferricyanide for those nerves bound for electron microscopy. Nerves used for light or electron microscopy were dehydrated in graded ethanol then a 1:1 mixture of ethanol and propylene oxide, followed by increasing concentrations of Araldite 502/ PolyBed 812 (catalog \#02595-1, Polysciences) in propylene oxide. Nerves were incubated in 100\% Araldite 502/PolyBed 812 under vacuum, switching embedding medium three times until being placed in an embedding mold, and then were cured over 3 successive days in an oven at 35,40 , then $60^{\circ} \mathrm{C}$. Optic nerves were sectioned using a Leica Ultramicrotome and a diamond knife (DiATOM) at $500 \mathrm{~nm}$ for light microscopy 
A

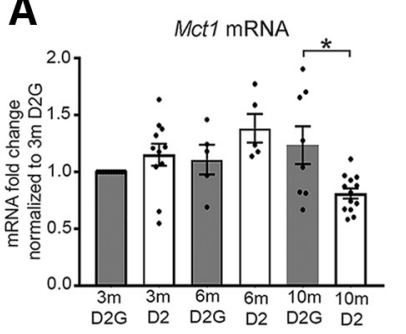

D

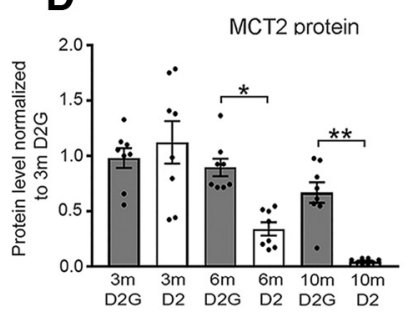

B

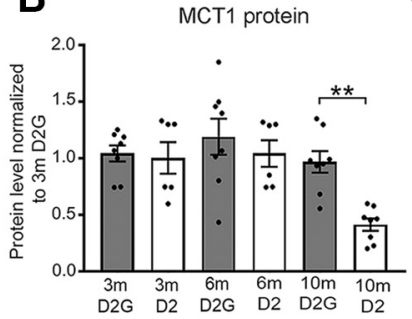

E

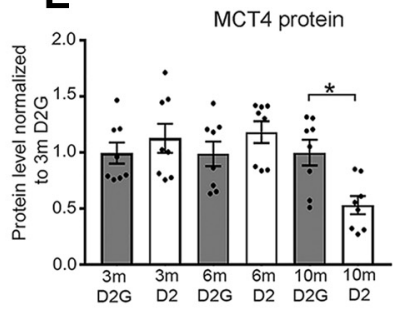

C
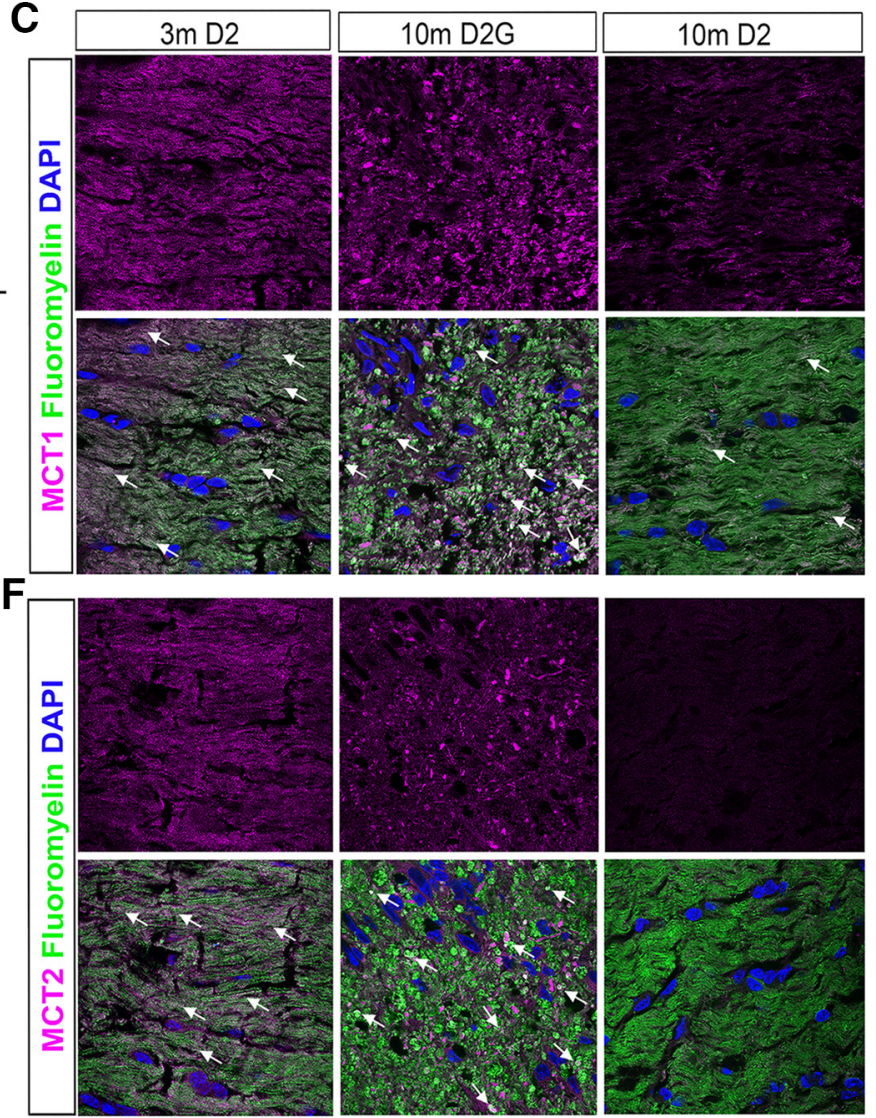

G
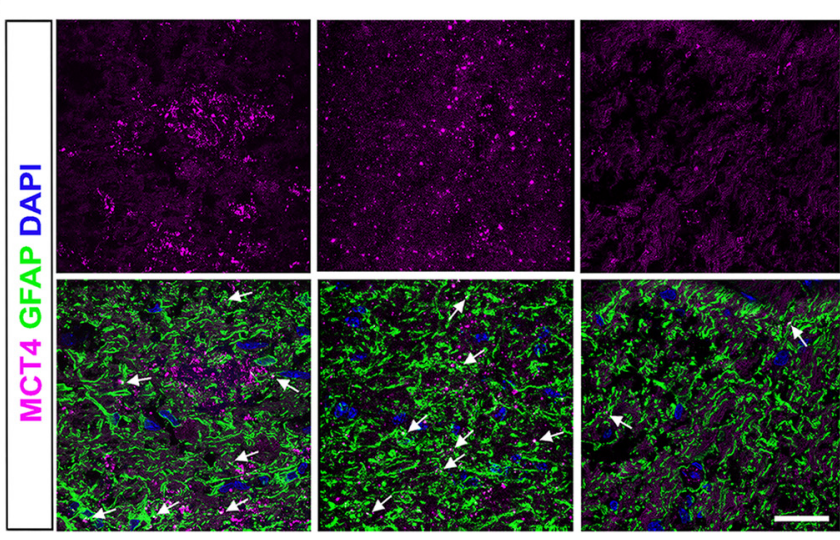

Figure 2. Monocarboxylate transporters downregulated with glaucoma pathology. A, Mct1 mRNA levels in 3-, 6-, and 10-month-old D2 and D2G ONs, normalized to Hprt mRNA then to 3-month-old D2G mRNA ( $n=5-13$ ONs/group). See Figure 2-1 available at https://doi.org/10.1523/JNEUROSCI.3652-17.2018.f2-1. B, D, E, MCT1, MCT2, and MCT4 protein levels in 3-, 6-, and 10-month-old D2G and D2 ONs, normalized to total protein and then to 3-month-old D2G protein levels ( $n=80 \mathrm{Ns} /$ group). $C, F, G$, Distribution of MCT1 (C), MCT2 (F), and MCT4 (G) in 3-month-old D2 and 10-month-old D2G and D2 ONs stained with FluoroMyelin (green) or immunolabeled with GFAP (green). Arrows indicate colocalization ( $n=3$ sections/ON, $n=60 \mathrm{Ns} / \mathrm{group})$. $\mathrm{H}$, Distribution of MCT2 in human control and glaucoma patient ONs, immunolabeled for $\beta$-tubulin (green) and stained with DAPI (blue). Arrows indicate colocalization ( $n=4$ sections/ON, $n=20 \mathrm{Ns} / \mathrm{group}$ ). See Figure 2-1 available at https://doi.org/10.1523/JNEUROSCI.3652-17.2018.f2-1. I-L, Percentage of mean fluorescence intensity in the R0I I, MCT1; J, MCT2; $K$, MCT4 (D2 and D2G mouse 0Ns); and $L$, MCT2, human ON; and (L) MCT2, human ON; and MCT2, human ONs (L). M, Quantification of the total number of RGC axons in 6-month-old D2, 10-month-old D2G, and 10-month-old D2 ONs. All values are presented as the mean \pm SEM, one-way ANOVA and Tukey's post hoc test. $A, F_{(5,47)}=4.579,{ }^{*} p=0.0141 ; \boldsymbol{B}, F_{(5,38)}=6.553,{ }^{* *} p=0.0076 ; D_{1}, F_{(5,42)}=16.14,{ }^{*} p=0.0054,{ }^{* *} p=$ $0.0013 ; \boldsymbol{E}, F_{(5,42)}=4.734,{ }^{*} p=0.0348 ; \boldsymbol{I}, F_{(2,51)}=173.2,{ }^{* * *} p=0.0001 ; \boldsymbol{J}, F_{(2,51)}=402.1,{ }^{* * *} p=0.0001 ; \boldsymbol{K}, F_{(2,51)}=192.6,{ }^{* * *} p=0.0001 ; \boldsymbol{L}, t_{(6)}=9.317,{ }^{* * *} p=0.0001$, two-tailed unpaired $t$ test. Scale bars, $\mathbf{C}, \boldsymbol{F}-\boldsymbol{H}, 20 \mu \mathrm{m}$.

and $70 \mathrm{~nm}$ for electron microscopy. Light microscopy sections were mounted on SuperFrost slides and stained with $\rho$-phenylenediamine (PPD). Electron microscopy sections were mounted on copper grids then stained with lead citrate and Uranyless (catalog \#22409, Electron Microscopy Sciences) before imaging on a JEOL 1400 transmission electron microscope at $15,000 \times$.

Axon counts. Optic nerve sections stained with PPD were counted by unbiased stereology using a $100 \times$ oil-objective and the optical fractionator approach within StereoInvestigator (MBF Bioscience). Approxi- mately 30 sampling sites $(10 \%)$ of each optic nerve cross section were counted. The coefficient of error (Gunderson) was $\leq 0.05$, ensuring a sufficient sampling rate.

Mitochondria counts. Two images were taken from each of five grids containing a cross section of an optic nerve sample (10 images total per sample). There were five samples for each of the control and ketogenic groups. All axonal mitochondria in each image were counted and the surface area measured. Data are expressed as the average number of mitochondria per $118 \mu \mathrm{m}^{2}$ field. 
A

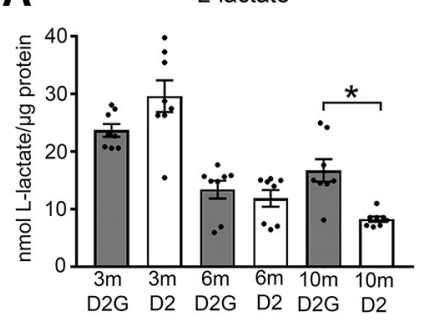

B

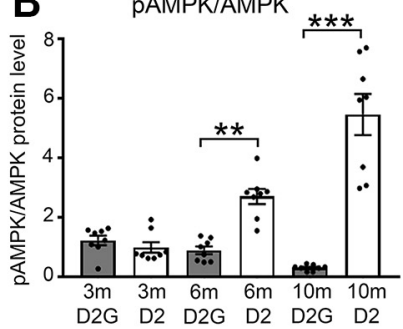

C
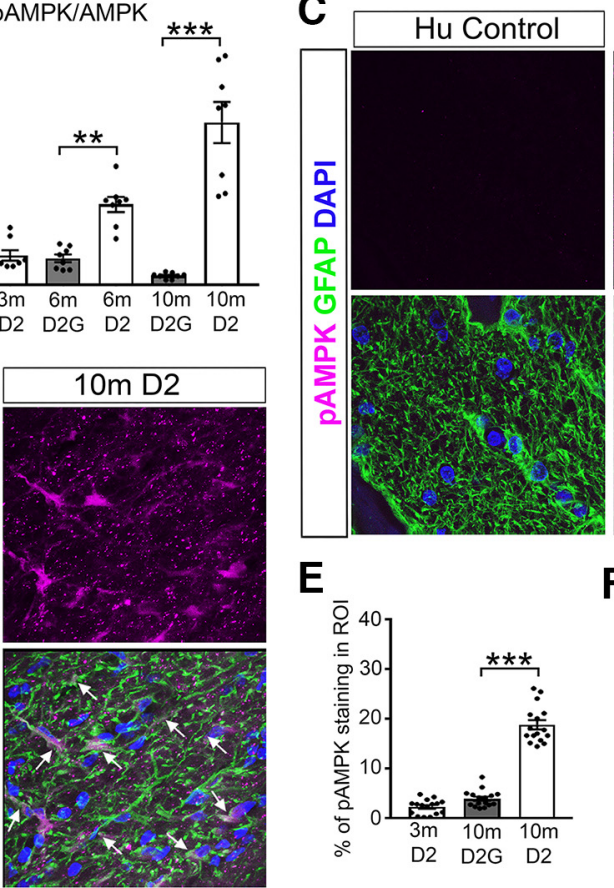

\section{$\mathbf{E}$}

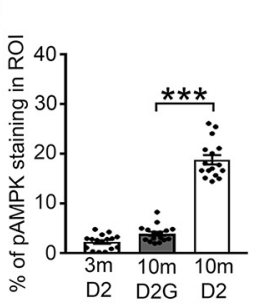

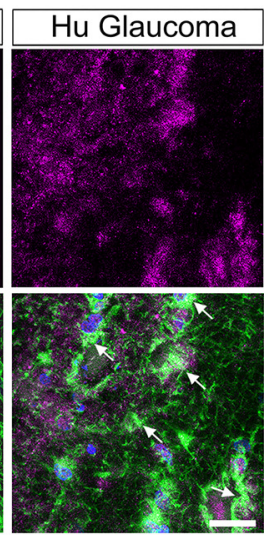

$\mathbf{F}$

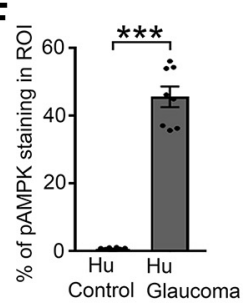

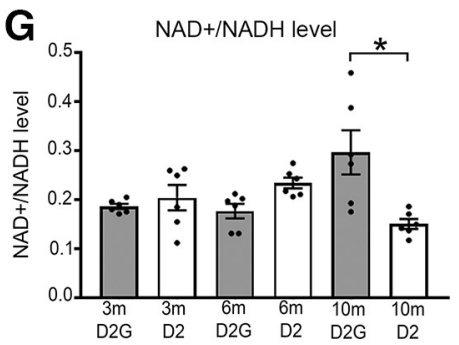
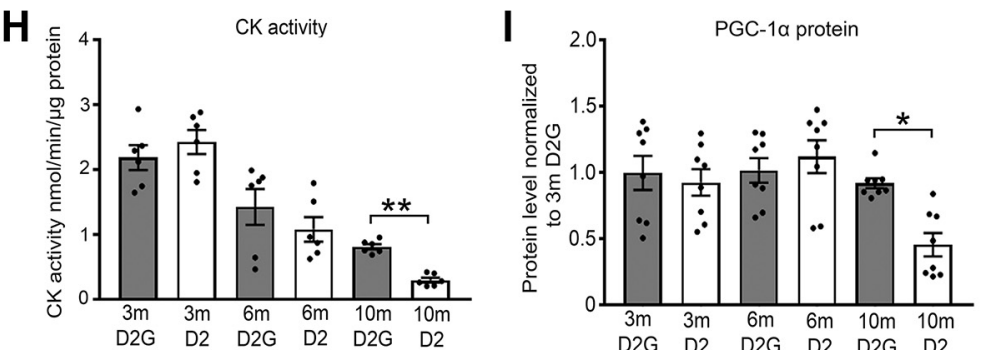

Figure 3. Low lactate level accompanies AMPK activation and limits mitochondrial biogenesis and metabolic cofactor pools. $A, \mathrm{~L}-$-lactate levels in 3-, 6-, and 10-month-old D2G and D2 0Ns ( $n=$ 8 ONs/group). $\boldsymbol{B}$, Ratio of pAMPK to AMPK protein in 3-, 6 -, and 10-month-old D2G and D2 ONs ( $n=8$ 0Ns/group). C, D, Phosphorylated AMPK immunofluorescence (magenta) and GFAP (green) micrographs $(C)$ of human control and glaucoma $0 \mathrm{Ns}(n=4$ sections/ON, $20 \mathrm{Ns} /$ group); and 3-month-old D2, and 10-month-old D2G and D2 mice $(n=3$ sections/0N, $60 \mathrm{Ns} / \mathrm{group} ; \boldsymbol{D})$. Arrows indicate colocalization of pAMPK and GFAP. $\boldsymbol{E}, \boldsymbol{F}$, Percentage of mean fluorescence intensity in the ROl for pAMPK 3-month-old D2, and 10-month-old D2G and D2 mice $(\boldsymbol{E})$ and humans $(\boldsymbol{F})$. G-I, Analyses of NAD ${ }^{+}$/NADH, CK activity, and PGC1- $\alpha$ levels in 3-, 6-, and 10-month-old D2G and D2 mice. G, NAD ${ }^{+}$normalized to NADH levels ( $n=6$ 0Ns/group). See Figure 3-1 available at https://doi.org/10.1523/JNEUROSCI.3652-17.2018.f3-1. $\boldsymbol{H}$, Creatine kinase activity normalized to total protein ( $n=6$ ONs/group). I, PGC1- $\alpha$ protein levels normalized to total protein levels and then to 3-month-old D2G protein levels $\left(n=8 \mathrm{ONs} /\right.$ group). All values are presented as the mean $\pm \mathrm{SEM}$, one-way ANOVA and Tukey's post hoc test. $\boldsymbol{A}, F_{(5,42)}=22.04,{ }^{*} p=0.0124 ; \boldsymbol{B}, F_{(5.42)}=$ $35.51,{ }^{* *} p=0.0032,{ }^{* * *} p=0.0001 ; \boldsymbol{E}, F_{(2,45)}=208.4,{ }^{* * *} p=0.0001 ; \boldsymbol{F}, t_{(14)}=14.79,{ }^{* * *} p=0.0001$, two-tailed unpaired $t$ test; $\boldsymbol{G}, F_{(5,30)}=5.061,{ }^{*} p=0.0012 ; \boldsymbol{H}, F_{(5,48)}=38.28,{ }^{* *} p=$ $0.0025 ; I F_{(5,42)}=5.43,{ }^{*} p=0.0231$. Scale bar, $C, D, 20 \mu \mathrm{m}$.

Human tissue. Human optic nerve tissue was obtained from the National Disease Research Interchange. All procedures comply with ethical regulations and were approved by the Institutional Review Board of the Northeast Ohio Medical University. Patients had received a positive diagnosis for glaucoma; no data regarding treatment were available. Age, gender, and general health status were matched for the control and glaucoma tissue; glaucoma patient was 61-year-old male in whom hypertension and glaucoma had been diagnosed. The control patient was 64year-old male with hypertension. In both cases, tissue was harvested within $1 \mathrm{~h}$ of death and fixed in $10 \%$ formalin. Proximal optic nerves were cryoprotected in $30 \%$ sucrose then sectioned at $50 \mu \mathrm{m}$ using a freezing sliding microtome. Sections were immunolabeled as described below.

Immunohistochemistry and microscopy. Freshly isolated eyes were immersion fixed in $4 \%$ paraformaldehyde for $30 \mathrm{~min}$ then cryoprotected in $30 \%$ sucrose with $0.02 \%$ sodium azide. Retinas were dissected out and vitreous removed. Optic nerves were similarly cryoprotected then embedded in Finetek O.C.T. (optimum cutting temperature; catalog \#14373-65, Fisher Scientific) and sectioned at $10 \mu \mathrm{m}$ on a cryostat. Human tissue was treated with TrueBlack Autofluoresence Quencher to mask the lipofuscin (1:300; catalog \#23007, Biotium). Immunolabeling for all tis- sues included washes in $0.1 \mathrm{M}$ PBS, then incubation in blocking solution ( $5 \%$ donkey serum, $1 \%$ Triton $\mathrm{X}-100$ in $0.1 \mathrm{~m}$ PBS) for $1 \mathrm{~h}$, primary antibody (diluted in $0.5 \% \mathrm{BSA}, 0.9 \% \mathrm{NaCl}, 1 \%$ Triton $\mathrm{X}-100$ in $0.1 \mathrm{M}$ PBS) for 18-72 h, washes, blocking solution for $30 \mathrm{~min}$, secondary antibody incubation for $2-18 \mathrm{~h}$, washes, DAPI labeling, then coverslipping with Fluoromount-G (Southern Biotech). Primary antibodies are listed in Table 1. Secondary antibodies are all from Jackson ImmunoResearch and include Alexa Fluor 488-conjugated anti-chicken IgG (RRID:AB_2340375), Alexa Fluor 594-conjugated anti-mouse IgG (RRID:AB_2340854), Alexa Fluor 594-conjugated anti-rabbit IgG (RRID:AB_2340621), Alexa Fluor 647conjugated anti-goat IgG (RRID:AB_2340437), Alexa Fluor 647-conjugated anti-mouse IgG (RRID:AB_2340862), and Alexa Fluor 647-conjugated antirabbit IgG (RRID:AB_2492288). In addition, FluoroMyelin (1:300; catalog \#MP 34651, Thermo Fisher Scientific) was used to stain the myelin of optic nerve.

For microscopy, a DMi8 confocal microscope integrated with application Suite X 3.1.1.15751 (Leica Microsystems) and an FSX100 Microscope integrated with FSX BSW software (Olympus America) were used. Micrographs were captured using the same exposure time settings among all groups. All the retina micrographs were captured from the central part of retina, and optic nerve micrographs were from proximal optic nerves. 
A

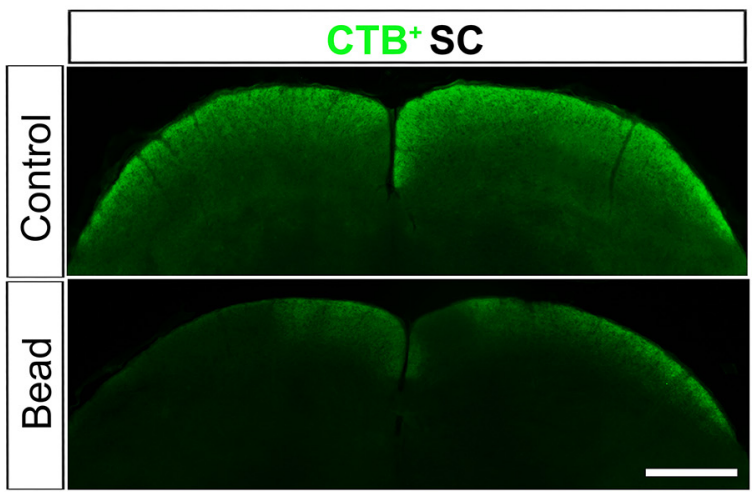

C

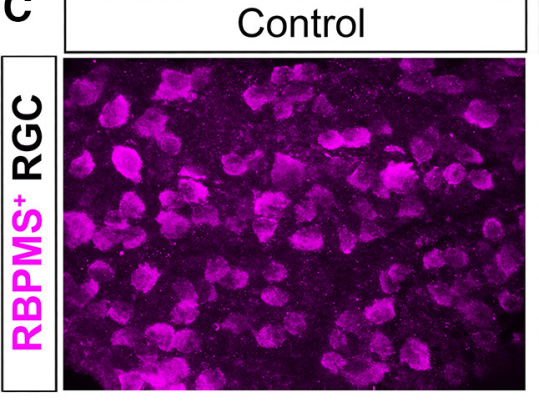

B

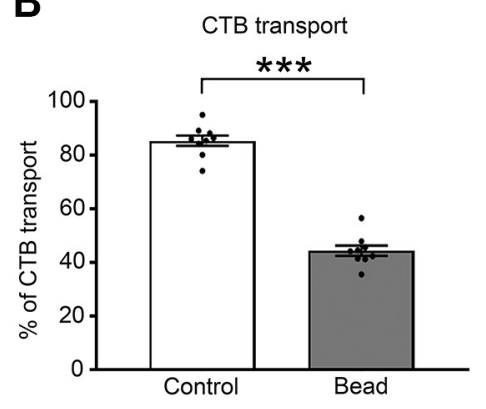

E

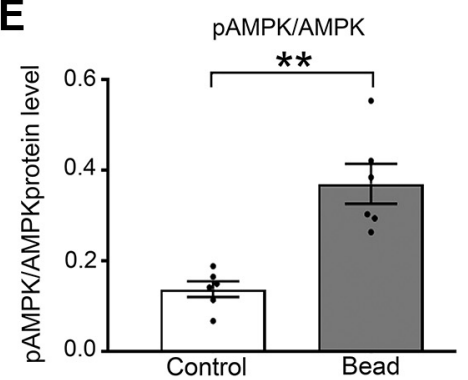

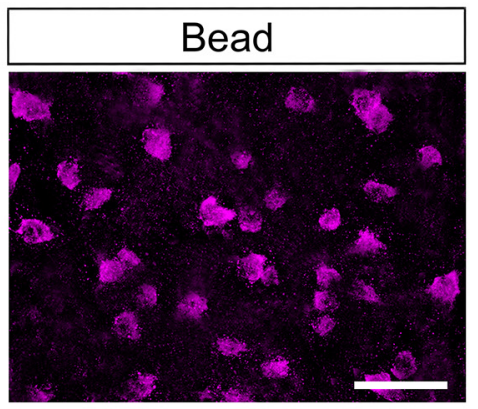

F

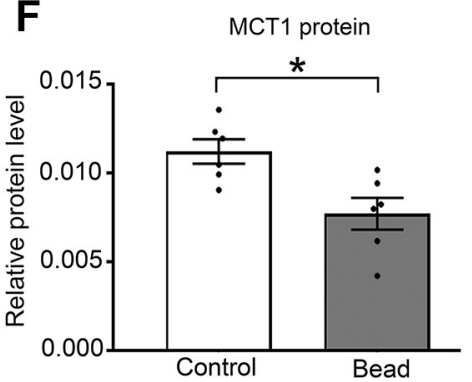

D

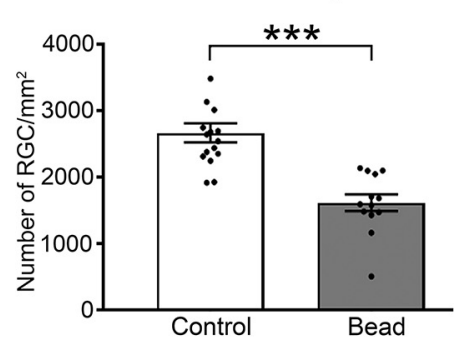

G

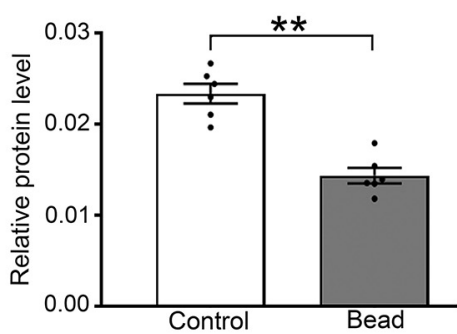

Figure 4. Monocarboxylate transport changes and AMPK activation occur with acute glaucoma injury. $A$, CTB (green) after intraocular injection from retina to SC of control and bead injected Mito-CFP mice. Dark regions of the superficial, retinorecipient areas of the SC indicate lack of axon transport from the retina. See Figure 4-1 available at https://doi.org/10.1523/JNEUROSCI.3652-17. 2018.f4-1. B, Percentage area fraction of (TB transport in SC ( $n=10$ per group). C, RGCs immunolabeled for the RGC-specific antigen RBPMS in control and bead-injected Mito-CFP mice. $\boldsymbol{D}$, Quantification of RGC density in control and bead-injected mice ( $n=16$ control mice; $n=14$ bead-injected mice). $\boldsymbol{E}-\boldsymbol{G}$, Protein analysis by capillary electrophoresis of pAMPK/AMPK (E), MCT1 $(\boldsymbol{F})$, and MCT2 (G). Proteins normalized to total protein $(n=60 \mathrm{Ns} / \mathrm{group})$. All values are presented as the mean \pm SEM, * ${ }^{*}$ two-tailed unpaired $t$ test. $\boldsymbol{B}, t_{(16)}=15.07,{ }^{* * *} p=0.0001 ; \boldsymbol{D}, t_{(27)}=$ $5.412,{ }^{* * *} p=0.0001 ; \boldsymbol{E}, t_{(10)}=4.165,{ }^{* * *} p=0.0019 ; \boldsymbol{F}, t_{(10)}=3.114,{ }^{*} p=0.0110 ; \boldsymbol{G}, t_{(10)}=6.536,{ }^{* *} p=0.00110$. Scale bars: $\boldsymbol{A}, 100 \mu \mathrm{m} ; \boldsymbol{C}, 50 \mu \mathrm{m}$.

Quantification of immunofluorescence was undertaken using an optical density measurement within regions of interest (ROIs) using Fiji-ImageJ (Schindelin et al., 2012). At least 12 ROIs were used per antigen for quantification.

Stereology. Whole mounted retinas were used to quantify RBPMSimmunolabeled retinal ganglion cells by unbiased stereology using a $20 \times$ objective and the optical fractionator approach within StereoInvestigator (MBF Bioscience). Between 35 and 40 sampling sites (10\%) of each retina were counted. The coefficient of error (Schmitz-Hof) was $\leq 0.05$, ensuring a sufficient sampling rate.

Biochemical assays. Optic nerves were isolated and flash frozen in liquid $\mathrm{N}_{2}$ or directly used for measurement of glycogen (Glycogen Assay Kit, catalog \#ab65620, Abcam), creatine kinase (CK) activity (Creatine Kinase Assay Kit, catalog \#K777-100, BioVision), L-lactate (L-Lactate Assay Kit, catalog \#700510, Cayman Chemical), NAD/NADH (reduced form of NAD; $\mathrm{NAD}^{+} / \mathrm{NADH}$ Assay Kit, catalog \#ab65348, Abcam), and $\beta$-hydroxybutyrate ( $\beta$-Hydroxybutyrate Assay Kit, catalog \#700190, Cayman Chemical). All the biochemical assays were performed according to the manufacturer instructions. Biochemical data were normalized by the total protein level of each optic nerve sample. Optic nerve total proteins were quantified using the Pierce BCA Protein Assay Kit (catalog \#23225, Thermo Fisher Scientific).
Succinate dehydrogenase and cytochrome c oxidase histochemistry. Freshly isolated optic nerves were flash frozen in liquid $\mathrm{N}_{2}$ and held at $-80^{\circ} \mathrm{C}$ until embedding in O.C.T. and sectioning on a cryostat. Both control and ketogenic ONs were embedded together, sectioned, and captured onto the same slide, then enzymatically reacted equally. For succinate dehydrogenase (SDH) histochemistry, optic nerve sections were incubated in $1.5 \mathrm{~mm}$ nitroblue tetrazolium (N6876), $130 \mathrm{~mm}$ sodium succinate (S2378), $0.2 \mathrm{~mm}$ phenazine methosulfate (P9625), and 1 mM sodium azide in $0.1 \mathrm{M} \mathrm{PBS} \mathrm{pH}=7.0$ for $40 \mathrm{~min}$ at $37^{\circ} \mathrm{C}$. Slides were washed 4 times for $10 \mathrm{~min}$ in PBS, dehydrated through a series of graded alcohols to xylenes, then coverslipped with DPX Mountant (Sigma-Aldrich). For cytochrome $c$ oxidase (COX) histochemistry, dried slides were incubated with $1 \times$ diaminobenzidine (D4293), $100 \mu \mathrm{M}$ cytochrome $c$ (D2506) and $4 \mathrm{IU} / \mathrm{ml}$ catalase (C9322) in $0.1 \mathrm{M} \mathrm{PBS}$, pH 7.0, for $40 \mathrm{~min}$ at $37^{\circ} \mathrm{C}$. As above, slides were washed in PBS, dehydrated through graded alcohols to xylenes, then coverslipped with DPX Mountant. All ingredients for SDH and COX histochemistry were obtained from Sigma-Aldrich.

$m R N A$ analysis. Fresh optic nerve tissue was collected from D2 and D2G ONs, and mRNA was isolated using TRIzol extraction (Thermo Fisher Scientific). mRNA was converted to cDNA (Verso cDNA Synthesis Kit, catalog \#AB1453B, Thermo Fisher Scientific) then analyzed using real-time quantitative PCR with an ABI 7900HT instrument (Applied 

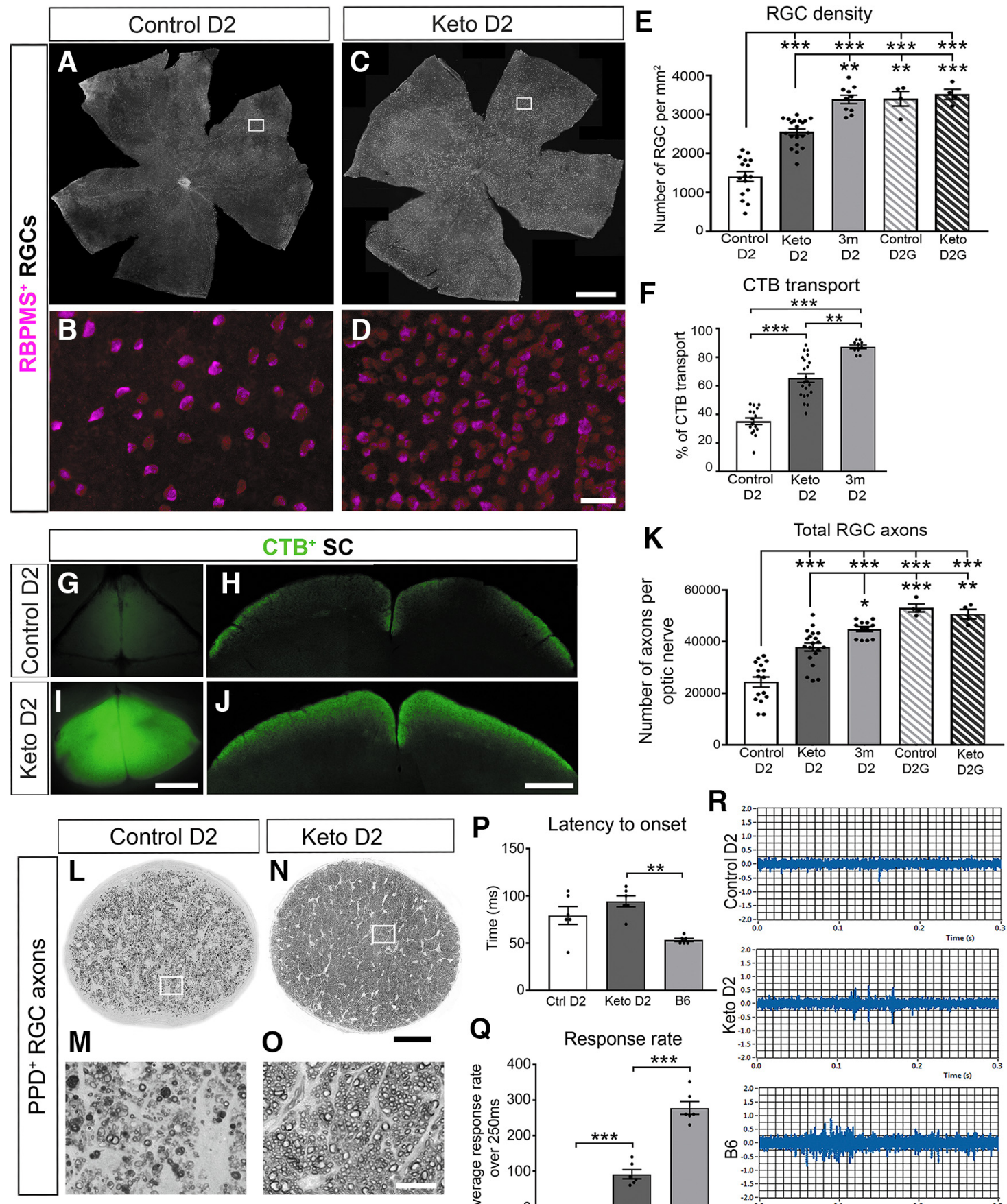
Control D2
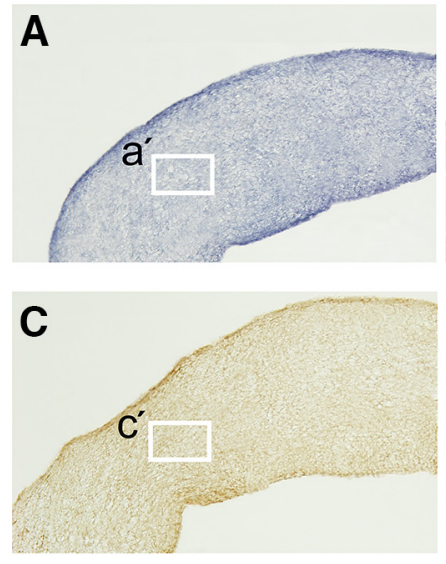

G
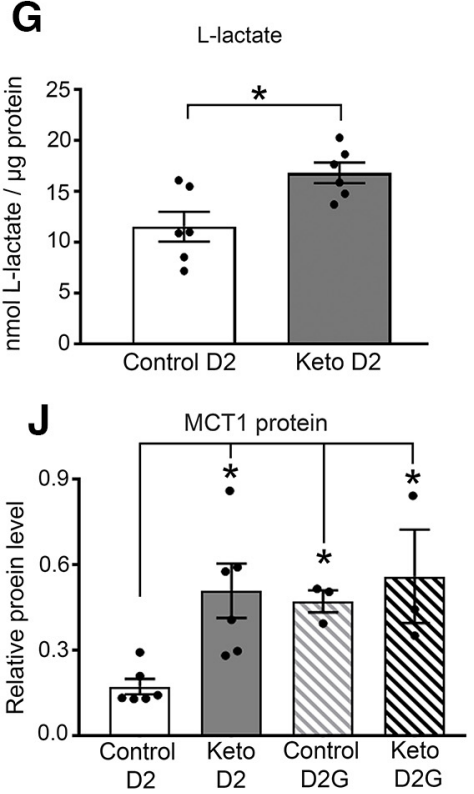

M

Phospho-AKT1 $1_{\text {Ser } 473} /$ Akt1

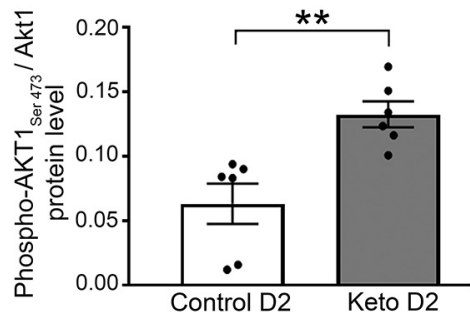

Keto D2
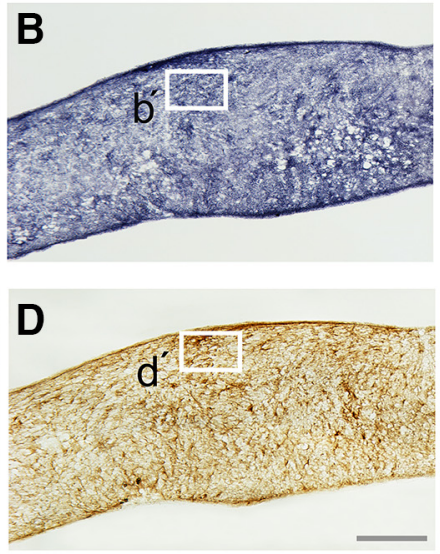

H
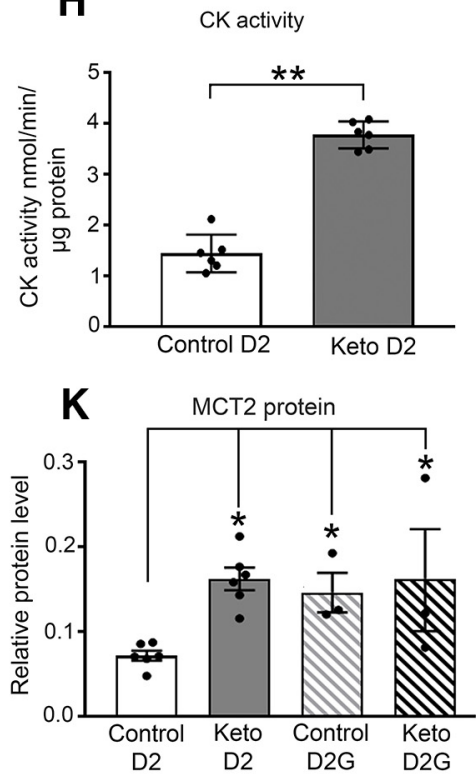

N Phospho-p70-S6K $\mathrm{K}_{\text {Thr } 389} /$ p70-S6K

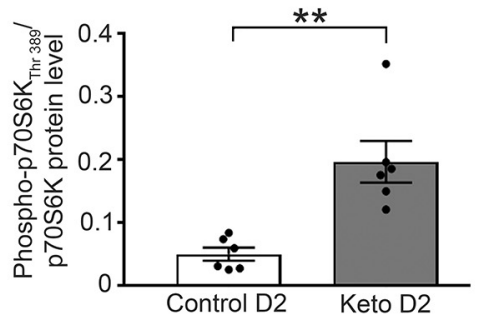

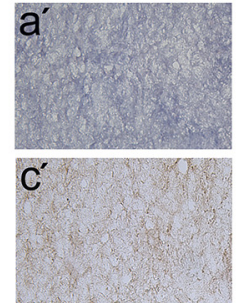
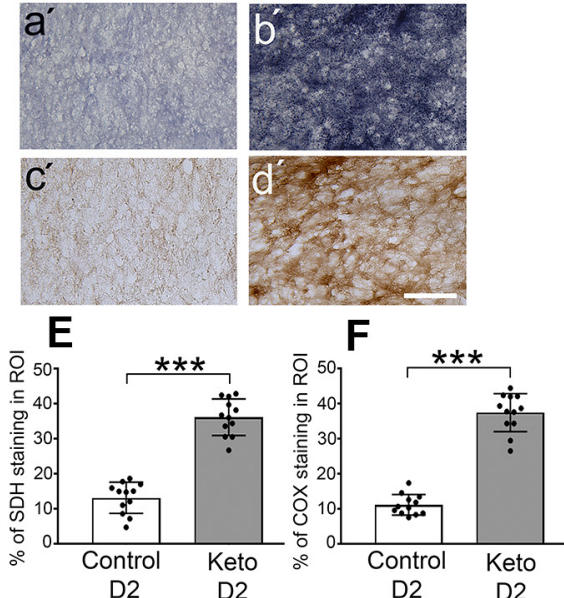
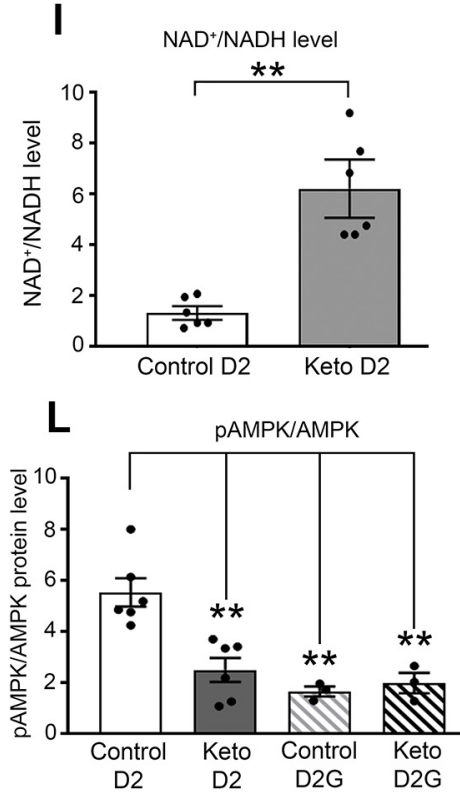

O Phospho-p70-S6K $\mathrm{K}_{\mathrm{Ser} 411} / \mathrm{p} 70-\mathrm{S6K}$

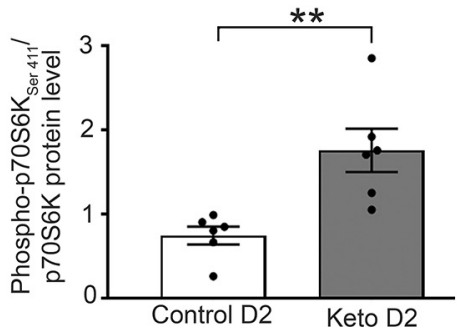

Figure 6. Ketogenic diet increases mitochondrial respiration, restores monocarboxylate transporters, reduces AMPK pathway activation, and activates the AKT—mTOR-p70S6K signaling pathway. $\boldsymbol{A}, \boldsymbol{a}^{\prime}$, SDH histochemistry of control diet-fed D2 ONs $(\boldsymbol{A})$ and high-magnification inset $\left(\boldsymbol{a}^{\prime}\right) . \boldsymbol{B}, \boldsymbol{b}^{\prime}$, SDH histochemistry of ketogenic diet-fed D2 ONs $(\boldsymbol{B})$ and high-magnification inset $\left(\boldsymbol{b}^{\prime}\right)$. $C, c^{\prime}$, COX histochemistry of control D2 ONs and high-magnification inset $\left(\boldsymbol{C}^{\prime}\right) . \boldsymbol{D}, \boldsymbol{d}^{\prime}$, COX histochemistry of a ketogenic D2 ON and high-magnification inset $\left(\boldsymbol{d}^{\prime}\right)$. $\boldsymbol{E}$, Quantification of SDH histochemistry as shown in $\boldsymbol{A}$ and $\boldsymbol{B}$ ( $n=40 \mathrm{Ns} /$ group, $n=3$ sections/nerve). $\boldsymbol{F}$, Quantification of COX histochemistry as shown in $\boldsymbol{C}$ and $\boldsymbol{D}$ ( $n=4$ 0Ns/group, $n=4$ sections/nerve). $\boldsymbol{G}, \mathrm{L}-$ lactate in control and keto D2 ONs ( $n=6 /$ group). $\boldsymbol{H}$, CK activity in control and keto D2 ONs $\left(n=6 /\right.$ group). $I$, NAD ${ }^{+} / \mathrm{NADH}$ ratio in control and keto D2 ONs ( $n=6 /$ group). G-I, Values normalized to total protein.J-0, Capillary electrophoresis protein analysis in control and keto D2 and D2G ONs $(n=6 /$ group), all normalized to total protein. J, MCT1 protein. $\boldsymbol{K}$, MCT2 protein. $\boldsymbol{L}$, Ratio of phosphorylated AMPK to AMPK protein. $\boldsymbol{M}$, Ratio of phosphorylated AKT1 $1_{\text {Ser } 473}$ to AKT1. $\boldsymbol{N}$, Ratio of p70S6K $\mathrm{K}_{\text {Thr } 389}$ to p70S6K protein. $\mathbf{0}$, Ratio of p70S6K $\mathrm{K}_{\text {Ser } 411}$ to p70S6K protein. See Figure 5-1 available at https://doi.org/10.1523/JNEUROSCI.3652-17.2018.f5-1 and Figure 6-1 available at https://doi.org/10.1523/JNEUROSCI.3652-17.2018.f6-1. All values are presented as the mean \pm SEM, two-tailed unpaired $t$ test, and one-way ANOVA and Tukey's post hoc test. $E: t_{(22)}=11.65,{ }^{* * *} p=0.0001 ; F: t_{(22)}=14.78,{ }^{* * *} p=0.0001 ; G: t_{(11)}=3.354,{ }^{*} p=0.0064 ; H: t_{(10)}=12.5,{ }^{* *} p=0.00101$; $I: t_{(10)}=6.20325,{ }^{* *} p=0.0013 ; J: F_{(3,14)}=4.751$, control D2 vs keto D2, ${ }^{*} p=0.0291$, control D2 vs control D2G, ${ }^{*} p=0.0461$, control D2 vs keto D2G, ${ }^{*} p=0.420 ; \boldsymbol{K}, F_{(3,14)}=4.354$, control D2 vs keto D2, ${ }^{*} p=0.0270$, control D2 vs control D2G, ${ }^{*} p=0.0356$, control D2 vs keto D2G, ${ }^{* *} p=0.043 ; L, F(3,14)=12.81$, control D2 vs keto D2 ${ }^{* *} p=0.0015$, control D2 vs control D2G, ${ }^{* *} p=$ 0.0011 , control D2 vs keto D2G, ${ }^{* *} p=0.0023 ; M: t_{(10)}=3.72,{ }^{* *} p=0.004 ; \boldsymbol{N}: t_{(10)}=4.232,{ }^{* *} p=0.0017 ; 0: t_{(10)}=3636,{ }^{* *} p=0.0046$. Scale bars: D (for $\left.\boldsymbol{A}-\boldsymbol{D}\right), 100 \mu \mathrm{m} ; \boldsymbol{d}^{\prime}$ (for $\boldsymbol{a}^{\prime}$ to $\boldsymbol{d}^{\prime}$ ), $20 \mu \mathrm{m}$. 
A

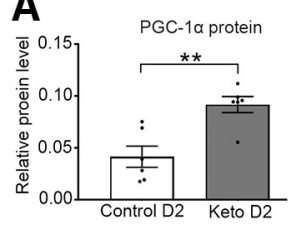

B

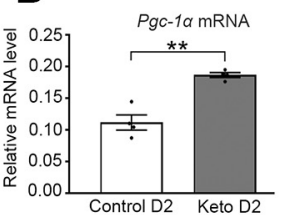

C

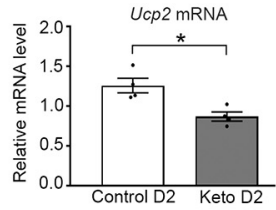

D
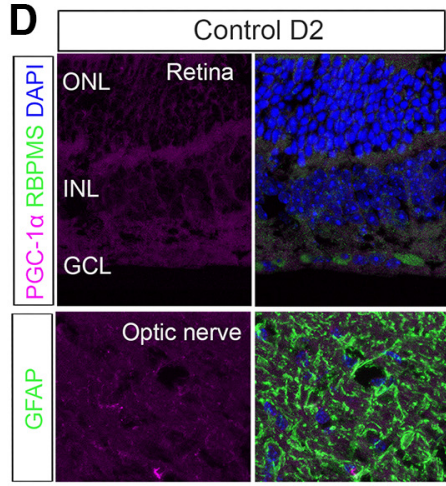

E

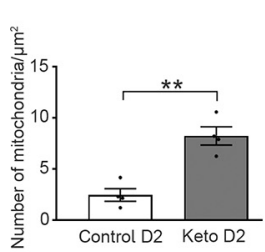

$\mathbf{F}$

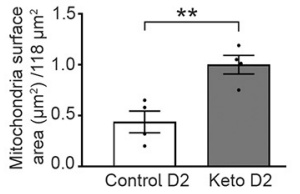

G
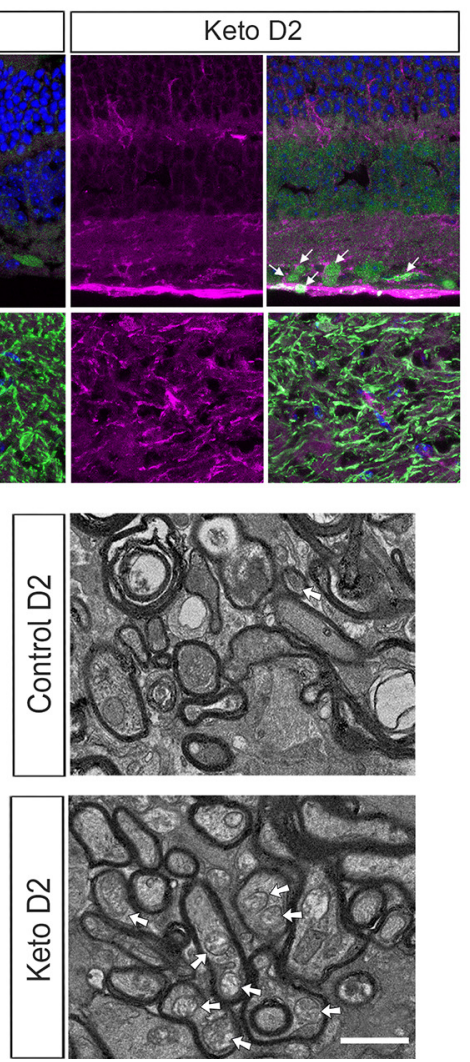

H
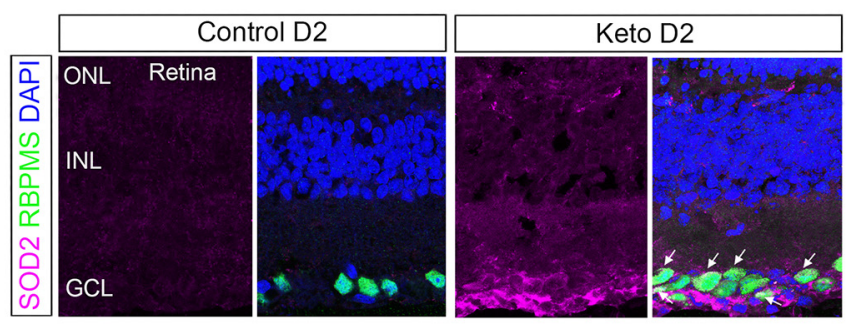

I
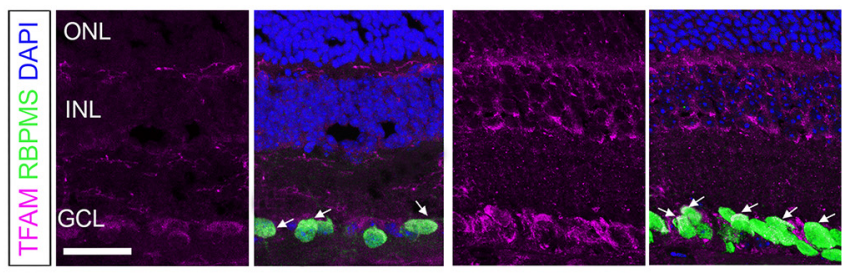

K
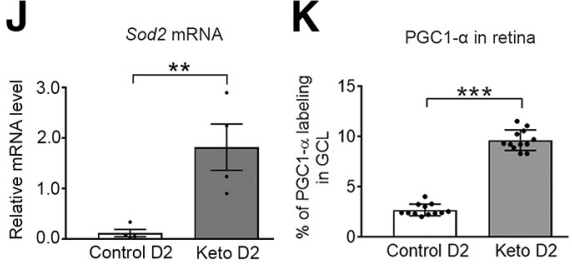

$\mathbf{L}$

PGC1- $\alpha$ in optic nerve
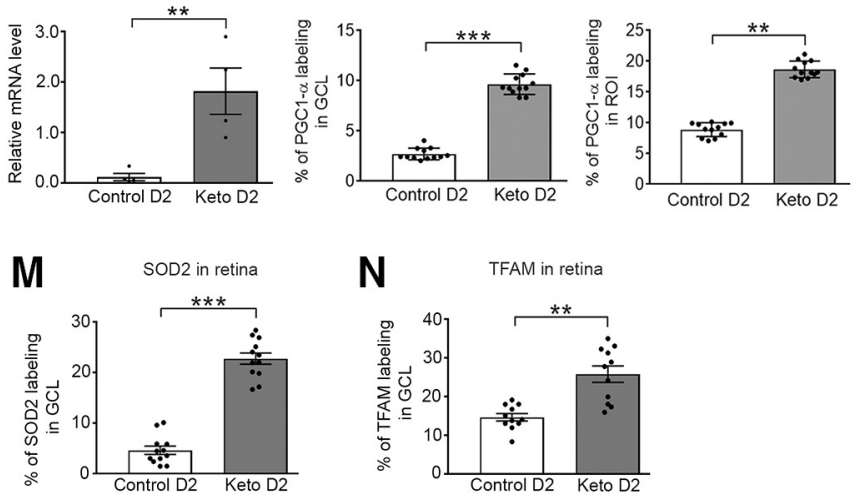

Figure 7. Ketogenic diet upregulates mitochondrial biogenesis and antioxidant response. $\boldsymbol{A}, \boldsymbol{B}, \mathrm{PGC}-1 \alpha$ protein $(n=6$ per group; $\boldsymbol{A})$ and $\mathrm{Pgc} 1 \mathrm{a}$ mRNA $(\boldsymbol{B})$ in control diet and keto D2 0 Ns $(n=$ 4/group). C, Ucp2 mRNA levels in control diet and keto D2 0Ns ( $n=4 /$ group). D, PCG-1 $\alpha$ immunofluorescence (magenta) in retina (top panels; RGC marker RBPMS in green) and ON (bottom panels; astrocyte marker GFAP in green). Arrows indicate RGC somata ringed with PGC-1 $\alpha$ labeling. $\boldsymbol{E}, \boldsymbol{F}$, Mitochondrial number $(\boldsymbol{E})$ and mitochondrial surface area $(\boldsymbol{F})$ in RGC axons within the $0 \mathrm{~N}(n=4$ ONs/group). G, Electron micrographs of control and keto D2 ONs. Arrows indicate mitochondria. $\boldsymbol{H}$, SOD2 immunofluorescence in control diet and keto D2 retinas. Arrows indicate colocalization of SOD2 with RBPMS. I, TFAM immunofluorescence in control diet and keto D2 retina. Arrows indicate colocalization of TFAM with RBPMS. J, Sod2 mRNA levels in control diet and keto D2 ONs ( $n=$ 4/group). Quantification of immunolabeling $\boldsymbol{K}, \mathrm{PGC}-1 \alpha$ in ganglion cell layer (GCL) of retina. $L, P G C-1 \alpha$ in proximal myelinated $0 N$. $M, S 0 D 2$ in GCL of retina; $\boldsymbol{N}$, TFAM in GCL of retina. All values are presented as the mean \pm SEM, two-tailed unpaired $t$ test. $A: t_{(10)}=3.917,{ }^{* *} p=0.0029 ; \boldsymbol{B}: t_{(6)}=5.938,{ }^{* *} p=0.0010 ; \boldsymbol{C}: t_{(6)}=3.569,{ }^{*} p=0.0118 ; \boldsymbol{E}: t_{(6)}=5.332,{ }^{* *} p=0.0018 ; \boldsymbol{F}: t_{(6)}=$ $4.007,{ }^{* *} p=0.0071 ; J: t_{(6)}=5.515,{ }^{* *} p=0.0105 ; K: t_{(22)}=20.41,{ }^{* * *} p=0.0001 ; L: t_{(22)}=19.28,{ }^{* *} p=0.001 ; M: t_{(22)}=13.13,{ }^{* * *} p=0.0001 ; N: t_{(20)}=4.809,{ }^{* *} p=0.0018 . S c a l e$ bar, I (for $D, H, I), 20 \mu \mathrm{m}$.

Profiler PCR Array for Mouse Mitochondria (catalog \#330001, QIAGEN) run on an Applied Biosystems QuantStudio 6K Flex 384 instrument.

Protein analysis. Fresh optic nerve tissue from D2 and D2G ONs was flash frozen in liquid nitrogen until homogenization in T-PER buffer (Thermo Fisher Scientific) with HALT protease and phosphatase inhibitors (catalog \#78442, Thermo Fisher Scientific) using three $3 \mathrm{~s}$ pulses at $10 \%$ amplitude from a Branson Sonicator. Protein samples were spun down at $10,000 \times g$ for $10 \mathrm{~min}$; supernatants were collected and analyzed by capillary tube-based immunoassay using the Wes, a ProteinSimple instrument that separates proteins by electrical charge in capillary tubes and allows binding of primary antibody then protein visualization within the capillary. The Wes permits analysis of very small amounts of protein, allowing us to assay individual optic nerves and quantify the amount of specific proteins within a lysate. Wes results (Fig. 1-1 available at https://doi.org/10.1523/ JNEUROSCI.3652-17.2018.f1-1) are normalized to total protein in the sample, as determined by capillary electrophoresis. Protein analysis was repeated at least three times with biological replicates.

Action potentials. Action potentials were recorded from the exposed SC. Mice were anesthetized using isoflurane ( $4 \%$ to induce and $2.5 \%$ to maintain) and secured in a stereotaxic device. Mice were given ketoprofen $(3-5 \mathrm{mg} / \mathrm{kg} ; 0.1 \mathrm{mg} / \mathrm{mouse}$, s.c.) for pain, and eyes were protected with ophthalmic ointment (PuraLube). The scalp was removed, and a steel post secured to the skull anterior to bregma using dental cement (ESPE Ketac-Cem Radiopaque, 3M). A drill was used to remove the skull to expose the region over the right SC where the sagittal and lambdoid sutures meet. Dura was cut away, and suction was used to remove the overlying visual cortex. Mice were then switched from isoflurane to urethane ( $2 \mathrm{~g} / \mathrm{kg} ; 0.05 \mathrm{~g} /$ mouse) anesthesia, with atropine ( $0.05 \mathrm{cc}$ of $15 \% /$ mouse) to control bronchial secretions. A fluorescent photomicrograph was taken to document the exposure of the SC and CTB tracing. The mouse, via the steel head post, was mounted within a Faraday cageshielded recording chamber. Systane Ultra eye drops kept the cornea moist during the recording. A fiber-optic cable directing LED light driven by a Grass stimulator, and flashing at $1 \mathrm{~Hz}$ was placed in front of the left eye. A tungsten electrode (catalog \#WE30031.5A3, MicroProbes for Life Science) fitted through a glass capillary and secured to a micromanipulator was advanced using a Piezo controller into the retino-recipient, superficial layers of the exposed SC. Light-driven postsynaptic potentials were re- 
Table 1. List of antibodies used for IHC and capillary electrophoresis analyses

\begin{tabular}{|c|c|c|c|c|}
\hline Antibody & Dilution & RRID & Company & Host \\
\hline AKT1 & $1: 50$ for Wes & $A B \_329827$ & Cell Signaling Technology & Rabbit \\
\hline AMPK $\alpha 12$ B7 & $1: 200$ for Wes & $A B \_2721834$ & Novus Biologicals & Mouse \\
\hline BDNF & 1:100 for IHC & AB_630940 & Santa Cruz Biotechnology & Rabbit \\
\hline Brn3a & 1:50 for IHC & $A B \_626765$ & Santa Cruz Biotechnology & Mouse \\
\hline$\beta$ Ill-tubulin & 1:1000 for IHC & $A B \_727049$ & Abcam & Chicken \\
\hline GLUT1 & $1: 200$ for $I H C, 1: 50$ for Wes & AB_790014 & Novus Biologicals & Rabbit \\
\hline GLUT3 & $1: 25$ for IHC and Wes & AB_2191306 & R\&D Systems & Mouse \\
\hline Glutamine Synthetase & 1:50 for Wes & AB_1127501 & Santa Cruz Biotechnology & Mouse \\
\hline GFAP & $1: 250$ for IHC & AB_10917109 & EMD Millipore & Mouse \\
\hline GFAP & 1:500 for IHC & AB_10013382 & Dako-Agilent & Rabbit \\
\hline \multirow[t]{2}{*}{ MCT1 } & $1: 25$ for IHC and Wes & AB_10841766 & Santa Cruz Biotechnology & Mouse \\
\hline & 1:50 for Wes & $A B \_2721836$ & Aviva Systems Biology & Rabbit \\
\hline \multirow[t]{2}{*}{ MCT2 } & 1:50 for Wes & AB_10855300 & Bioss & Rabbit \\
\hline & $1: 250$ for IHC & $A B \_2254765$ & Santa Cruz Biotechnology & Goat \\
\hline MCT4 & 1:50 for Wes & AB_2189333 & Santa Cruz Biotechnology & Rabbit \\
\hline NRF2 & $1: 25$ for IHC & AB_2618882 & Developmental Studies Hybridoma Bank & Mouse \\
\hline RBPMS & $1: 200$ for IHC & AB_10720427 & GeneTex & Rabbit \\
\hline Phospho-AKT $T_{\text {Ser } 473}$ & 1:50 for Wes & AB_329825 & Cell Signaling Technology & Rabbit \\
\hline pAMPK $\alpha 1_{\text {Thr } 172}$ & $1: 100$ for $I H C, 1: 50$ for Wes & AB_11032916 & Novus Biologicals & Rabbit \\
\hline p7056K & $1: 50$ for Wes & $A B \_331676$ & Cell Signaling Technology & Rabbit \\
\hline Phospho-p70S6K Thr 389 & 1:50 for Wes & AB_330944 & Cell Signaling Technology & Rabbit \\
\hline Phospho-p70S6K $\mathrm{K}_{\text {Ser } 411}$ & $1: 25$ for Wes & $A B \_2182257$ & Santa Cruz Biotechnology & Mouse \\
\hline SOD2 & 1:100 for IHC & AB_2191814 & Santa Cruz Biotechnology & Mouse \\
\hline TFAM & $1: 50$ for IHC & AB_10610743 & Santa Cruz Biotechnology & Mouse \\
\hline
\end{tabular}

IHC, Immunohistochemistry.

Table 2. TaqMan gene expression assays

\begin{tabular}{ll}
\hline Gene & Assay number \\
\hline Hprt & Mm00446968_m1 \\
Slc16a3 (Mct4) & Mm00446102_m1 \\
Scl16a7 (Mct2) & Mm00441442_m1 \\
Slc16a1 (Mct1) & Mm01306379_m1 \\
Glul (GS) & Mm00725701_s1 \\
Foxo3 & Mm01185722_m1 \\
Gfap & Mm01253033_m1 \\
Actb & Mm00607939_s1 \\
Slc2a3 (Glut3) & Mm00441483_m1 \\
Slc2a1 (Glut1) & Mm00441480_m1 \\
UCP2 & Mm00627599_m1 \\
\hline
\end{tabular}

corded from three different sites within each SC through a bandpass filter, Dagan amplifier, with resultant postsynaptic potentials documented in a custom-written LabVIEW software (University of California, Berkeley, Berkeley, CA) module. Data are reported as a latency to onset of activity and average response rate over the first $250 \mathrm{~ms}$ of activity. Activity is defined as spikes that exceed 2 SDs of spontaneous activity.

Experimental design and statistical analysis. Statistical analyses were undertaken using GraphPad Prism software version 7.0. Data were analyzed by unpaired, two-tailed $t$ test when comparing across groups within a strain, or within a group across strains. In cases for which data were not normally distributed, a nonparametric Mann-Whitney test to compute the $95 \%$ confidence interval for the difference between medians was used. One-way ANOVA and Tukey's multiple-comparison post hoc test were used when making comparisons across multiple groups within a strain, or across multiple groups within an outcome measure. $p<0.05$ was considered significant, and data are reported as the mean \pm SEM.

\section{Results}

Optic nerve axons are metabolically stressed in chronic glaucoma

Astrocytes store glycogen, a polysaccharide form of glucose that can be mobilized to provide energy for astrocytes, and potentially for axons. We measured glycogen in a time course of myelinated optic nerves from D2 and D2G mice (a glaucoma strain and its control, respectively; see Materials and Methods), finding a significant decrease in glycogen in the D2 mouse with increasing age and IOP ( 6 and 10 months of age; Fig. $1 A, F_{(5,30)}=18.59$, ${ }^{* *} p=$ $\left.0.0022,{ }^{* *} p=0.00011\right)$. We analyzed glutamine synthetase (GS) mRNA and protein levels, finding no changes in GS mRNA levels across the D2 and D2G ONs (Fig. 1-1 available at https://doi.org/ 10.1523/JNEUROSCI.3652-17.2018.f1-1). There was a substantial increase in GS protein in the D2G ON from 3 to 6 months of age, but no significant changes in GS protein in either strain from 6 to 10 months (Fig. 1-1 available at https://doi.org/10. 1523/JNEUROSCI.3652-17.2018.f1-1). Glycogen depletion occurs during a period of increased astrocyte activity, morphological change (Bosco et al., 2016), and proliferation (Son et al., 2010) indicated by the significant upregulation of Gfap mRNA at 6 and 10 months in the D2 ON (Fig. 1-1 available at https://doi.org/10.1523/JNEUROSCI.3652-17.2018.f1-1).

To determine whether energy substrate (glucose, lactate) provision contributes to glaucoma pathogenesis, we evaluated the transporters that handle these substrates. Optic nerve glial cells express glucose transporter 1 (GLUT1) while axons express GLUT3. GLUT1 protein was relatively stable across ages and IOP with the exception of the ONs from 10-month-old D2 mice, which showed a significant decrease in GLUT1 as measured by capillary electrophoresis (Fig. $1 B$ and Fig. 1-1 available at https://doi.org/ 10.1523/JNEUROSCI.3652-17.2018.f1-1; $F_{(5,42)}=6.463,{ }^{* *} p=$ $0.0077)$. Immunolabeling for GLUT1 showed clear puncta on the plasma membrane of astrocytes and oligodendrocytes at all ages except the nerves from 10-month-old D2 mice, in which it was barely detectable (Fig. 1C). Despite this, baseline Glut1 mRNA levels were significantly higher in D2 ONs compared with D2G ONs at 3 months, but were not statistically different in D2 and D2G mice at 10 months (Fig. $1 D, F_{(3,20)}=3.209,{ }^{* *} p=0.001$ ). D2 mice had significantly more axon-specific Glut 3 mRNA at 3 and 10 months of age than D2G mice (Fig. $1 E, F_{(5,37)}=15.58,{ }^{* *} p=$ $\left.0.0023,{ }^{* * *} p=0.0001\right)$. GLUT3 protein showed a trend toward increase with age in both glaucoma and control strains, though 
there were no statistical differences across groups (Fig. $1 F$ ). Strong GLUT3 immunolabeling was evident along RGC axon membranes in both strains and all ages (Fig. $1 G$, arrows). Quantification of immunolabeling corroborates the significant decreases in GLUT1 for 10-month-old D2 mice (Fig. $1 H ; F_{(2,51)}=$ $\left.210.4,{ }^{* *} p=0.0001\right)$ and lack of difference across age and strain for GLUT3 (Fig. 1I).

Lactate, pyruvate, and ketone bodies such as $\beta$-hydroxybutyrate are transported across membranes through MCTs. MCT isoforms differ in their substrate-binding affinities and kinetics, making MCT1, the transporter primarily expressed in astrocytes, oligodendrocytes, and endothelial cells (Lee et al., 2012), which are best suited for lactate export, and MCT2, the transporter primarily expressed in neurons (Pierre et al., 2002; Simpson et al., 2007), for lactate uptake. MCT4, also with kinetics suited for export, is also expressed in astrocytes (Rafiki et al., 2003). Mct1 mRNA and protein were significantly decreased in 10-month-old D2 myelinated ONs compared with 10 -month-old D2G ONs [Fig. 2A-C (A: $\left.\left.F_{(5,47)}=4.579,{ }^{\star} p=0.0141 ; B: F_{(5,38)}=6.553,{ }^{* *} p=0.0076\right)\right]$. Here, MCT1 is colocalized with astrocytes and oligodendrocytes (Fig. 2C,I, analysis). The intact FluoroMyelin staining (Fig. 2C,F) and GFAP immunolabeling (Fig. 2G) indicate that these decreases are not accompanied by astrocyte or oligodendrocyte loss. Mct2, specific for axons, and Mct4 showed stable mRNA levels from 3 to 10 months in ONs (Fig. 2-1 available at https://doi.org/ 10.1523/JNEUROSCI.3652-17.2018.f2-1), but significant MCT2 protein decreases occur in the D2 ON at both 6 and 10 months of age (Fig. $\left.2 D, F_{(5,42)}=16.14,{ }^{\star} p=0.0054,{ }^{\star *} p=0.0013\right)$. There is no loss of axons at 6 months in D2 ONs, and only modest loss at 10 months (Dengler-Crish et al., 2014), as shown by axon quantification of 10-month-old D2 ONs (Fig. 2M). Immunolabeling showed barely detectable MCT2 and MCT4 protein in the 10month-old D2 ONs (Fig. 2F, G,J,K, analysis). Notably lower MCT2 and MCT4 labeling was observed in the ONs from a glaucoma patient compared with an age-matched control subject (Fig. 2H,L and Fig. 2-1 available at https://doi.org/10.1523/ JNEUROSCI.3652-17.2018.f2-1). These significant decreases in MCT1 and MCT4 occur without concomitant loss of astrocytes (Fig. 1-1 available at https://doi.org/10.1523/JNEUROSCI. 3652-17.2018.f1-1), indicating that these proteins are downregulated with glaucoma progression.

Decreases in both GLUT1 and MCTs in the ONs suggest severely compromised substrate movement from glia to axons. To determine whether the decrease in MCTs is accompanied by changes in monocarboxylate availability, we measured lactate levels in a time course of D2 and D2G ON. L-lactate was significantly decreased in 10-month-old D2 ONs compared with D2G ONs (Fig. $3 A, F_{(5,42)}=22.04,{ }^{\star} p=0.0124$ ). Energy shortages in tissue activate $5^{\prime}$ AMP-activated protein kinase (AMPK), a master cellular energy sensor (Garcia and Shaw, 2017). The ratio of activated (phosphorylated) AMPK to inactive AMPK was significantly increased in the D2 ON starting at 6 months and continuing at 10 months (Fig. $3 B ; F_{(5,42)}=35.51,{ }^{* *} p=0.0032,{ }^{* *} p=$ $0.0001)$. Immunolabeling for phosphorylated AMPK (pAMPK) shows a profound increase in astrocytes, with puncta throughout the tissue, in 10-month-old D2 ONs (Fig. $3 D, E, F_{(2,45)}=208.4$, $\left.{ }^{* *} p=0.0001\right)$. Human ONs from a patient in whom glaucoma had been diagnosed also showed significantly increased pAMPK immunolabeling, colocalized with the astrocyte marker GFAP, compared with the age-matched control patient (Fig. $3 C, F, t_{(14)}=$ $14.79,{ }^{* *} p=0.0001$, two-tailed unpaired $t$ test).

To further confirm that the optic nerve faced an energy deficit, we measured $\mathrm{NAD}^{+}$and NADH levels and creatine kinase activity.
CK regulates energy by generating ATP from phosphocreatine. The ratio of $\mathrm{NAD}^{+}$to $\mathrm{NADH}$ (Fig. $3 G, F_{(5,30)}=5.061,{ }^{*} p=0.0012$ ) and $\mathrm{NAD}^{+}$levels (Fig. 3-1 available at https://doi.org/10.1523/ JNEUROSCI.3652-17.2018.f3-1, $F_{(5,30)}=6.129,{ }^{*} p=0.0096$ ) were significantly decreased in the 10 -month-old D2 ONs compared with 10-month-old D2G ONs. Significant decreases in total NAD were observed at 6 and 10 months in the D2 compared with D2G mice (Fig. 3-1 available at https://doi.org/10.1523/JNEUROSCI. 3652-17.2018.f3-1). There was an age-related decline in creatine kinase activity in both D2 and D2G ONs. In addition, creatine kinase activity in the 10-month-old D2 ONs was significantly decreased compared with 10-month-old D2G ONs (Fig. $3 \mathrm{H}$, $\left.F_{(5,48)}=38.28,{ }^{* *} p=0.0025\right)$. Significant decreases in peroxisome proliferator-activated receptor $\gamma$ coactivator $1-\alpha$ (PGC- $1 \alpha$ ) have been observed in aged D2 retina (Guo et al., 2014), suggesting a deficit in new mitochondria generation, so we tested whether there might be a concomitant decrease in ON. PGC- $1 \alpha$ is significantly decreased in 10-month-old D2 ONs compared with D2G ONs (Fig. 3I, $F_{(5,42)}=5.43,{ }^{\star} p=0.0231$ ).

\section{Optic nerve is metabolically stressed in acute glaucoma}

To test whether these transporter changes and evident metabolic vulnerability were peculiar to the D2 mouse model of glaucoma, we subjected mice to acute glaucoma instigated by injection of $8 \mu \mathrm{m}$ magnetic beads into the anterior chamber of the eye to block aqueous humor outflow and raise IOP to glaucomatous levels (Sappington et al., 2010). The bead-injected, hypertensive eyes were cumulatively elevated $200 \pm 10 \mathrm{mmHg} / \mathrm{d}$ over the contralateral, normotensive eyes, indicating a significant IOP increase approximately equivalent to $5 \mathrm{mmHg}$ over normal (Fig. 4-1 available at https://doi.org/10.1523/JNEUROSCI.3652-17.2018. f4-1). CTB injected into the eye was used to assess axon transport deficits to the SC, the main retinal target in mice. An example of intact axon transport (normotensive control) versus transport deficit (bead-injected hypertensive) is shown in cross sections of the SC in Figure 4A. Quantification of tracer label showed the SC corresponding to the normotensive eyes with $85.39 \pm 2.53 \%$ of collicular area positive for CTB, while only $44.68 \pm 2.47 \%$ of collicular area exhibited tracer label in SC of ocular hypertensive eyes (Fig. $4 B, t_{(16)}=15.07,{ }^{* *} p=0.0001$ ). Six weeks of ocular hypertension also led to extensive loss of retinal ganglion cells in hypertensive eyes (Fig. $4 C, D, t_{(27)}=5.412,{ }^{* * *} p=0.0001$ ). Similarly to the D2 findings, optic nerves from hypertensive eyes showed an almost threefold increase in the pAMPK/AMPK ratio (Fig. $4 E, t_{(10)}=4.914,{ }^{* *} p=0.0006$ ), indicating substantial energy deprivation. The glaucomatous optic nerve also exhibited notable decreases in MCT1 and MCT2 protein levels [Fig. $4 F, G$ $\left(\boldsymbol{F}: t_{(10)}=3.114,{ }^{*} p=0.0110 ; \boldsymbol{G}: t_{(10)}=6.536,{ }^{* *} p=0.00110\right]$. There were no changes in GLUT1 and GLUT3 protein levels (Fig. 5-1 available at https://doi.org/10.1523/JNEUROSCI.3652-17. 2018.f5-1). These data indicate that, similarly to the glaucomatous D2 mice, the optic nerve is susceptible to metabolic vulnerability when eyes are subjected to acute IOP elevation.

\section{Forced respiration resolves metabolic stress in chronic glaucoma}

To determine whether the loss of MCTs and the lactate they provide is central to subsequent degeneration of the optic nerve, we provided 9-month-old D2 or D2G mice with 8 weeks of a ketogenic or a control diet. Putting mice on a carbohydrate-free diet forces the mitochondria in both astrocytes and neurons to provide all of the ATP because there would be little to no glycolysis unless gluconeogenesis, an energy-intensive process, also oc- 
Table 3. Ketogenic and control mouse indices

\begin{tabular}{|c|c|c|c|c|c|c|c|c|}
\hline & $\begin{array}{l}\text { Baseline IOP } \\
(\mathrm{mmHg})\end{array}$ & $\begin{array}{l}\text { Terminal IOP } \\
\text { (mmHg) }\end{array}$ & $\begin{array}{l}\text { Baseline } \\
\text { weight }(\mathrm{g})\end{array}$ & $\begin{array}{l}\text { Terminal } \\
\text { weight }(\mathrm{g})\end{array}$ & $\begin{array}{l}\text { Food intake } \\
\text { by week }(\mathrm{g})\end{array}$ & $\begin{array}{l}\text { kCal } \\
\text { by week }\end{array}$ & $\begin{array}{l}\text { Plasma } \beta H B \\
\text { levels (mm) }\end{array}$ & Retina $\beta$ HB levels $\mu \mathrm{g} / \mu \mathrm{g}$ of protein \\
\hline \multicolumn{9}{|l|}{ D2 keto } \\
\hline Male $(n=14)$ & $16.8 \pm 1.2$ & $18.0 \pm 0.7$ & $36.2 \pm 1.0$ & $41.9 \pm 1.1$ & $17.4 \pm 0.6$ & $117 \pm 1.1$ & $0.50 \pm 0.02$ & \multirow[t]{2}{*}{$0.2008 \pm 0.00065 n=8$ retina } \\
\hline Female $(n=10)$ & $16.8 \pm 1.2$ & $18.1 \pm 1.7$ & $27.6 \pm 1.1$ & $31.4 \pm 1.1$ & $12.2 \pm 0.5$ & $82.64 \pm 1.0$ & $0.4 \pm 0.03$ & \\
\hline \multicolumn{9}{|l|}{ D2 control } \\
\hline Male $(n=12)$ & $17.1 \pm 0.7$ & $16.9 \pm 0.7$ & $37.2 \pm 1.1$ & $37.9 \pm 1.1$ & $29.9 \pm 0.7$ & $117 \pm 1.5$ & $0.08 \pm 0.003$ & \multirow[t]{2}{*}{$0.0029 \pm 0.00014 n=4$ retina } \\
\hline Female $(n=12)$ & $17.1 \pm 0.8$ & $16.8 \pm 0.9$ & $26.3 \pm 1.0$ & $26.0 \pm 1.0$ & $20.4 \pm 13$ & $80.1 \pm 1.1$ & $0.10 \pm 0.003$ & \\
\hline \multicolumn{9}{|l|}{ D2G keto } \\
\hline Male $(n=5)$ & $12.1 \pm 0.8$ & $12.1 \pm 0.5$ & $32.9 \pm 2.2$ & $37.2 \pm 1.2$ & $16.5 \pm 0.5$ & $111.5 \pm 2.0$ & \multirow[t]{2}{*}{$0.2 \pm 0.020$} & \\
\hline Female $(n=2)$ & $12.2 \pm 0.4$ & $11.9 \pm 0.1$ & $24.3 \pm 2.1$ & $27.0 \pm 1.0$ & $11.5 \pm 2$ & $77.8 \pm 1.5$ & & \\
\hline \multicolumn{9}{|l|}{$\mathrm{D} 2 \mathrm{G}$ control } \\
\hline Male $(n=2)$ & $11.9 \pm 0.8$ & $12.1 \pm 0.8$ & $32.1 \pm 0.9$ & $32.5 \pm 1.0$ & $28.8 \pm 2$ & $112 \pm 1.0$ & \multirow[t]{2}{*}{$0.07 \pm 0.001$} & \\
\hline Female $(n=2)$ & $12.1 \pm 0.2$ & $12.0 \pm 0.5$ & $24.6 \pm 0.5$ & $24.5 \pm 0.9$ & $20.2 \pm 13$ & $79.2 \pm 1.1$ & & \\
\hline
\end{tabular}

$n=$ Number of mice. Numbers are averages per mouse; all values are the mean \pm SEM.

curred. In this diet, the liver uses $\beta$-oxidation to turn the longand medium-chain triglycerides of the KD into ketone bodies ( $\beta$-hydroxybutyrate and acetoacetate) that cross the blood-brain barrier and can be converted for use in the Krebs cycle. Table 3 contains the baseline and terminal IOP and weight, the food intake, and the plasma and retina $\beta \mathrm{HB}$ levels in the D2 mice and plasma $\beta \mathrm{HB}$ levels in the D2G mice used in the study. There was no change in IOP with the diet. D2 and D2G mice gained weight on the KD despite lower food intake; the higher number of kilocalories per gram of the KD allowed the mice eating the KD to consume less food than the control mice (Table 3 ). As expected, there were significant increases in plasma and retina $\beta \mathrm{HB}$ levels in the $\mathrm{D} 2$ and plasma $\beta \mathrm{HB}$ in the $\mathrm{D} 2 \mathrm{G}$ mice eating the KD.

The KD significantly protected the RGC number in the retinas of the ketogenic group compared with controls (Fig. $5 A-E, F_{(4,49)}=$ $\left.53.92,{ }^{* *} p=0.0026,{ }^{* *} p=0.0001\right)$, with RGC density for ketogenic D2 mice of $2487 \pm 105$ versus $1444 \pm 184$ cells $/ \mathrm{mm}^{2}$ for control diet D2; $3517 \pm 130$ cells $/ \mathrm{mm}^{2}$ for ketogenic D2G mice, and $3405 \pm 185$ cells $/ \mathrm{mm}^{2}$ for D2G control mice. For reference, a 3-month-old D2 mouse with no pathology has $3418 \pm 116$ cells $/ \mathrm{mm}^{2}$. There was significantly greater transport of CTB to the SC from the retina in ketogenic D2 mice $(61.82 \pm 3.73 \%$ vs $35.5 \pm 2.83 \%$ in control diet D2 mice) as well, indicating improved axon transport function or axon protection (Fig. $5 \mathrm{~F}-\mathrm{J}$, $\left.F_{(2,45)}=72.04,{ }^{* *} p=0.00106,{ }^{* *} p=0.0001\right)$. We examined the axon number with PPD-stained semi-thin cross sections of optic nerve to determine any effect on axon loss. ONs from D2 ketogenic mice were significantly more intact, with 37,828 \pm 1766 axons/ON compared with $24,827 \pm 2460$ axons/ON in the D2 mice eating the control diet (Fig. $5 K-O, F_{(2,45)}=36.58,{ }^{\star} p=$ $0.0148,{ }^{* *} p=0.0001$ ), indicating axon protection. D2G ketogenic mice had 50,648 \pm 1472 axons/ON, and D2G control mice had 53,052 \pm 1384 axons/ON. For reference, a 3-month-old D2 ON with no pathology had 44,843 \pm 957 axons/ON. To confirm that protected RGCs and optic nerve axons in the ketogenic mice were functional, we recorded light-driven action potentials in the superior colliculus, subtending the entire nasal-temporal extent of the collicular retinotopic map, the target for $\sim 90 \%$ of all RGCs in the mouse (Ellis et al., 2016). Both the ketogenic and control diet D2 groups exhibited very low spontaneous firing rates when compared with B6 mice (Kaneda and Isa, 2013). We were unable to drive collicular neurons with visual stimuli in the D2 control diet mice. At no point did they diverge significantly from their spontaneous firing rate. In the D2 ketogenic mice, we were able to drive cells in $55 \%$ of the penetrations, defined as firing rates greater than twice the SD of spontaneous activity. Though we recorded clear visual responses in the D2 ketogenic mice, these responses exhibited much longer latencies compared with B6 mice (Fig. 5P, $52.5 \mathrm{~ms}$ for B6 mice, $94.2 \mathrm{~ms}$ for ketogenic D2 mice, $\left.F_{(2,15)}=10.17,{ }^{*} p=0.0013\right)$. Given this delay, we measured the average firing rate for the $250 \mathrm{~ms}$ after response onset to account for any possible slowing of response kinetics in the ketogenic D2 mice (Fig. 5Q; $\left.F_{(2,15)}=120.9,{ }^{* *} p=0.0001\right)$. Responsive neurons in the ketogenic mice averaged $91 \mathrm{~Hz}$ firing rate during the post onset $250 \mathrm{~ms}$ time window and a peak firing rate of $333 \mathrm{~Hz}$; there were no responsive neurons in the control diet SC. For the B6 mice, the response window averaged $304 \mathrm{~Hz}$ with a peak rate of $1160 \mathrm{~Hz}$.

\section{Ketogenic diet increases energy availability}

As anticipated, the KD promoted mitochondrial respiration, as measured by histochemistry for electron transport chain complex II (SDH) and complex IV (COX) activities [Fig. 6A-F (E: $\left.\left.t_{(22)}=11.65,{ }^{* *} p=0.0001 ; \boldsymbol{F}: t_{(22)}=14.78,{ }^{* * *} p=0.0001\right)\right]$. SDH activity was significantly higher in the D2 ketogenic ON compared with the control, as visualized (Fig. $6 B, b^{\prime}$ ) and quantified (Fig. $6 E$ ) in the optic nerve. COX activity was also significantly higher in the ONs of KD-fed D2 mice versus those of control diet mice, as visualized in Figure 6, $C, c^{\prime}, F$ (quantified). We evaluated several metabolic biochemical indices and pathways to understand the mechanism of KD neuroprotection. L-Lactate levels (Fig. $6 G, t_{(11)}=3.354,{ }^{\star} p=0.0064$ ) and creatine kinase activity (Fig. $6 H, t_{(10)}=12.5,{ }^{* *} p=0.00101$ ), normally reduced in the D2 mouse at these ages, were significantly increased in the $\mathrm{D} 2$ mice eating the KD compared with the control diet. $\mathrm{NAD}^{+} / \mathrm{NADH}$ ratio, $\mathrm{NAD}^{+}$, and total NAD were significantly increased in the ketogenic ONs compared with control ONs [Fig. $6 I\left(t_{(10)}=6.20325,{ }^{* *} p=0.0013\right)$, and Fig. $5-1 F$ available at https://doi.org/10.1523/JNEUROSCI.3652-17.2018.f5-1 $\left(t_{(10)}=4.025,{ }^{* *} p=0.001\right)$, and Fig. $5-1 \mathrm{H}$ available at https:// doi.org/10.1523/JNEUROSCI.3652-17.2018.f5-1 $\left(t_{(10)}=6.025\right.$, $\left.\left.{ }^{* *} p=0.001\right)\right]$. There was no difference between D2 ketogenic and control ON levels of NADH (Fig. 5-1 available at https://doi.org/10. 1523/JNEUROSCI.3652-17.2018.f5-1; negative control slide data in Fig. 6-1 available at https://doi.org/10.1523/JNEUROSCI.365217.2018.f6-1).

With only ketone bodies for fuel, we observed a significant upregulation of MCT1 and MCT2 protein in the D2 ONs [Fig. 6J, K $\left.\left(J: F_{(3,14)}=4.751,{ }^{\star} p=0.0173 ; K: F_{(3,14)}=4.354,{ }^{\star} p=0230\right)\right]$, but not MCT4 (Fig. 5-1 available at https://doi.org/10.1523/ JNEUROSCI.3652-17.2018.f5-1). These data indicate a response by oligodendrocytes (MCT1) and axons (MCT2) to 
A

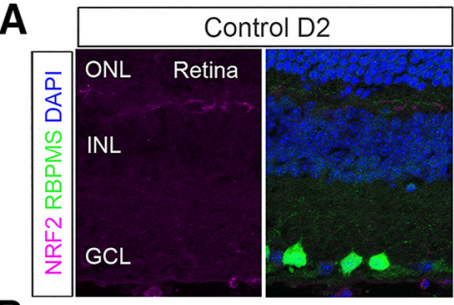

B

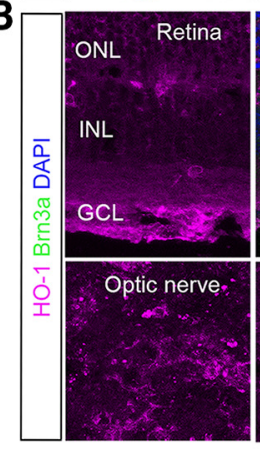

C

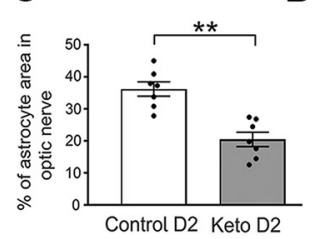

D

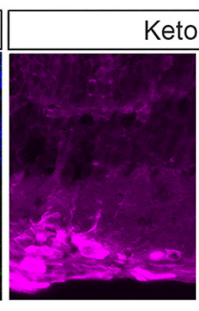

Keto D2
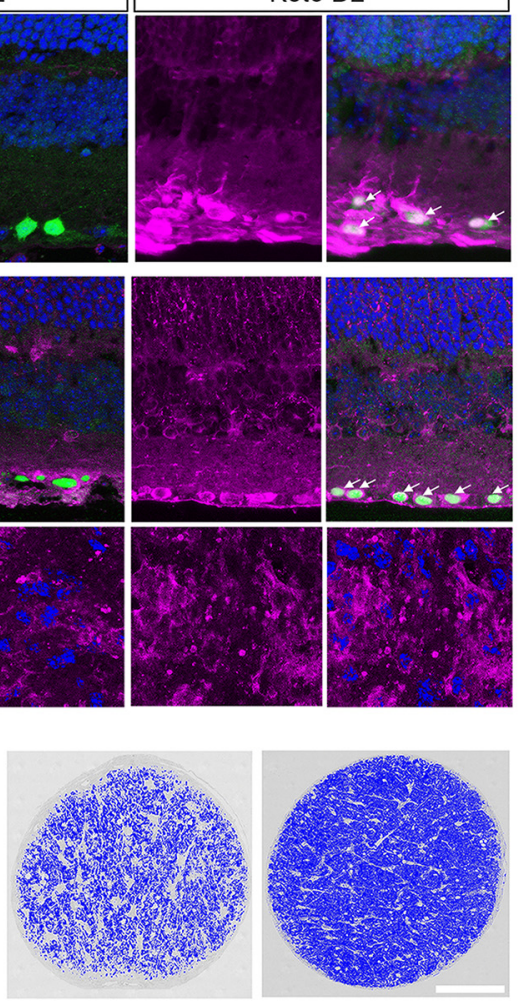

E
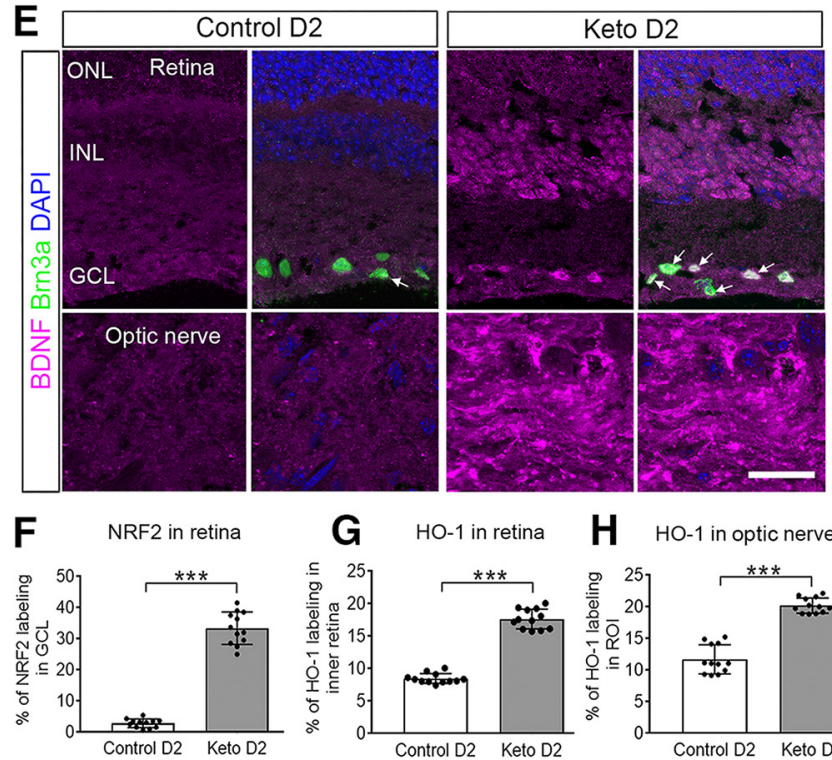

G HO-1 in retina

H HO-1 in optic nerve
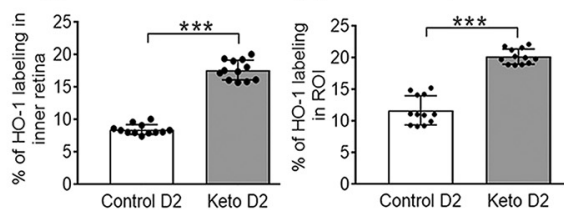

I

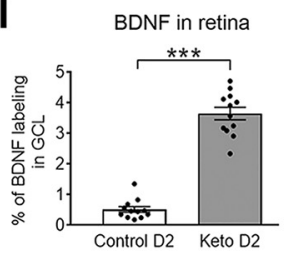

J BDNF in optic nerve

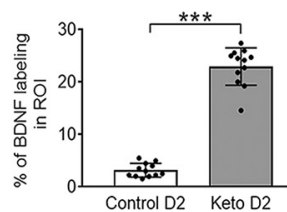

Figure 8. Ketogenic diet upregulates antioxidant response, limits glial hypertrophy, and upregulates BDNF. A, NRF2 immunofluorescence (magenta) in control diet and keto D2 retinas. Arrows indicate somata in which Nrf2 has translocated to the nucleus of RGCs labeled with RBPMS (green). B, H0-1 (magenta) and Brn3a (green) immunofluorescence in control diet and keto D2 retina and ON ( $n=4 /$ group). C, Astrocyte hypertrophy analysis in ON cross sections from control and keto D2 mice. D, Examples of thresholding used to calculate area of astrocyte hypertrophy in control (left) and ketogenic diet (right) $0 \mathrm{Ns}$. Scale bar, $100 \mu \mathrm{m}$. Dark blue areas are intact axons; light areas are astrocytes. $\boldsymbol{E}, \mathrm{BDNF}$ (magenta) immunofluorescence in control diet and keto D2 retinas also immunolabeled for Brn3a for RGCS (green) and ONs. Arrows and white color indicate colocalization of BDNF with Brn3a. $F-I$, Percentage of immunolabeling by ROl across analysis depicted in $\boldsymbol{A}, \boldsymbol{B}$, and $\boldsymbol{E}$. Analysis was undertaken in three sections per tissue, with four retinas or ONs per group. $F$, NRF2 in GCL of retina. $G, H 0-1$ in inner retina. $\boldsymbol{H}$, HO- 1 in proximal myelinated ON. $I$, BDNF in GCL of retina.J, BDNF in proximal myelinated ON. All values are presented as the mean \pm SEM, two-tailed unpaired $t$ test. $C: t_{(12)}=4.983,{ }^{* *} p=0.003 ; F: t_{(22)}=19.56,{ }^{* * *} p=0.0001 ; G: t_{(22)}=18.65$, ${ }^{* * *} p=0.0001 ; \boldsymbol{H}: t_{(22)}=11.38,{ }^{* * *} p=0.0001 ; \boldsymbol{I}: t_{(22)}=13.93,{ }^{* * *} p=0.0001 ; J: t_{(22)}=18.01,{ }^{* * *} p=0.0001$. Scale bar, $\boldsymbol{E}($ for $\boldsymbol{A}, \boldsymbol{B}$ and $\boldsymbol{E}), 20 \mu \mathrm{m}$.

enable greater substrate delivery to the axon. There was no change in the protein levels of GLUT1 and GLUT3 in ketogenic versus control mouse ONs (Fig. 5-1 available at https://doi.org/10.1523/JNEUROSCI.3652-17.2018.f5-1).

\section{Shift to mitochondrial biogenesis and catabolism with ketogenic diet}

A shift from anabolic to catabolic processes occurred in the ketogenic D2 ONs, based on a significant decrease in the ratio of pAMPK to AMPK (Fig. $6 L, F_{(3,14)}=12.81,{ }^{* *} p=0.001$ ) with KD, a reversal of the significant $\mathrm{pAMPK}$ upregulation observed in the 10-month-old D2 ONs (Fig. 3B). To further explore evidence of catabolism, we measured AKT activation as well as p70 ribosomal S6 kinase (p70S6K), a downstream target of mammalian target of rapamycin (mTOR). There was significantly increased pAKT1 and p70S6K in the ketogenic D2 ONs [Fig. 6M-O (M: $t_{(10)}=$ $3.72,{ }^{* *} p=0.004 ; N: t_{(10)}=4.232,{ }^{* *} p=0.0017 ; O: t_{(10)}=3636$, $\left.\left.{ }^{* *} p=0.0046\right)\right]$. For p70S6K, we evaluated phosphorylation at Thr-389 and Ser-411; the latter site controls p70S6K activation through phosphorylation of Thr-389 (Hou et al., 2007). The target of p70S6K, S6, is a ribosomal subunit that participates in protein translation. It has been shown that MCTs are upregulated at the level of translation (Chenal et al., 2008). Also in keeping with mTOR activation, PGC- $1 \alpha$ protein and mRNA were significantly increased in the ketogenic D2 ONs over control ONs [Fig. $7 A, B\left(A: t_{(10)}=3.917,{ }^{* *} p=0.0029 ; B: t_{(6)}=5.938,{ }^{* *} p=\right.$
$0.0010)$ ], suggesting potentially increased mitochondrial biogenesis. A PGC- $1 \alpha$ target, UCP2 (Wu et al., 1999), had significantly lower mRNA in the keto D2 ONs (Fig. $7 C, t_{(6)}=3.569,{ }^{\star} p=$ 0.0118 ) and retina (Fig. 5-1 available at https://doi.org/10.1523/ JNEUROSCI.3652-17.2018.f5-1). Immunofluorescent labeling of retina and ON for PGC- $1 \alpha$ indicated high levels of PGC- $1 \alpha$ in nerve fiber layer glia (astrocytes) as well as within RGCs (Fig. $7 D$ ). To ascertain whether PGC- $1 \alpha$ activity led to mitochondrial biogenesis, axon mitochondria were quantified in electron micrographs taken from ketogenic and control myelinated proximal ONs [Fig. $7 E-G\left(\boldsymbol{E}, t_{(6)}=5.332,{ }^{* *} p=0.0018 ; \boldsymbol{F}, t_{(6)}=4.007\right.$, $\left.\left.{ }^{* *} p=0.0071\right)\right]$. In axons, mitochondria number (Fig. $7 E$ ) and surface area (Fig. $7 F$ ) were significantly increased in the ketogenic ON compared with control. Increased surface area of the ketogenic ON mitochondria suggests the increased mitochondrial number is not due to fission events. Retinal immunolabeling for SOD2 and TFAM (transcription factor A, mitochondrial) showed increased levels of SOD2 and TFAM expression in RGCs with the $\mathrm{KD}$, indicating upregulated antioxidant response and greater mitochondrial biogenesis in the ketogenic D2 retinas [Fig. $7 \mathrm{H}, \mathrm{M}$, $\left.\left(t_{(22)}=13.13,{ }^{* *} p=0.0001\right), I, N\left(t_{(20)}=4.809,{ }^{* *} p=0.0018\right)\right]$.

\section{Antioxidant response increased with ketogenic diet}

Forced respiration might increase ROS, a byproduct of oxidative phosphorylation. To determine whether this transpired with the $\mathrm{KD}$, we immunolabeled retina and $\mathrm{ON}$ with an antibody against 


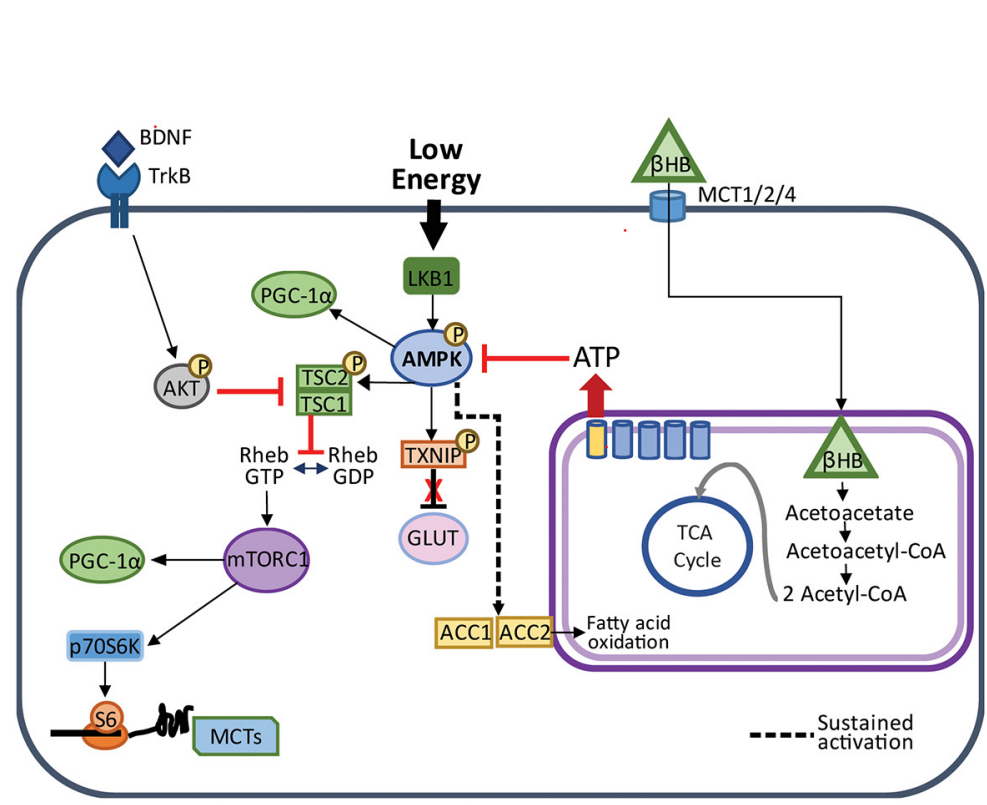

Ketogenic Intervention
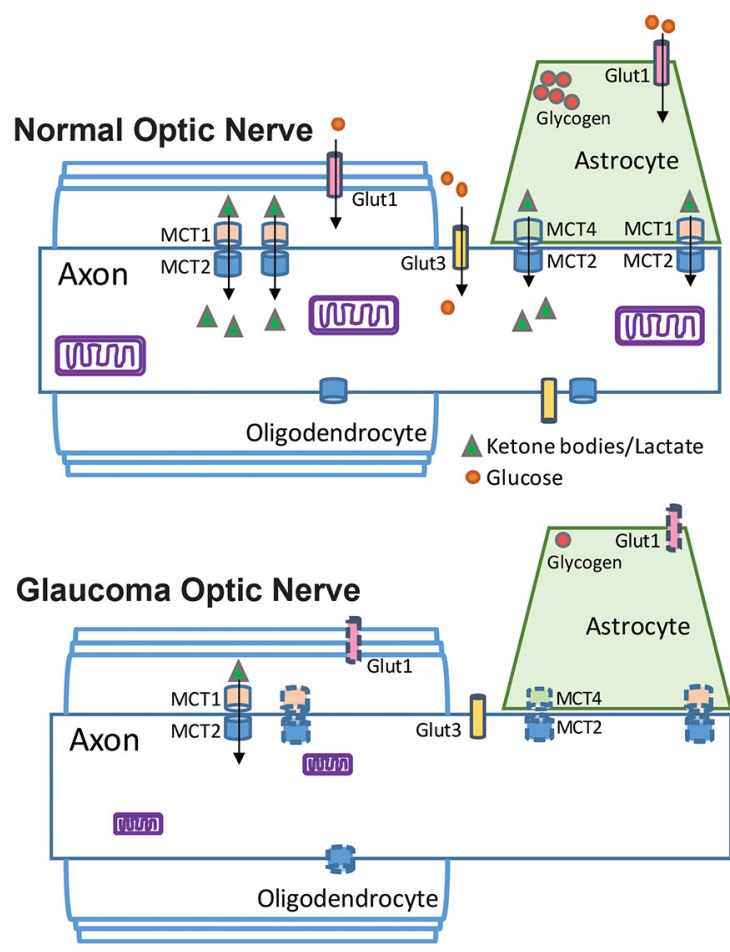

Figure 9. Glucose and monocarboxylate transporter complement in optic nerve, and intracellular pathways regulating the response to low energy and ketogenic diet. Right, Top, Normal optic nerve showing mitochondria within the axon, and glycogen storage in the astrocyte contacting the axonal node of Ranvier. The glucose transporters GLUT1 (on astrocytes and oligodendrocytes) and GLUT3 (on axons) are distributed across their respective cells. The monocarboxylate transporters (MCT2 on axons, MCT1 on oligodendrocytes, and MCT1 and MCT4 on astrocytes) display kinetics that favor the movement of ketone bodies and lactate from the glia to the neurons. Right, Bottom, Glaucomatous optic nerve shows a reduction in mitochondria size (Coughlin et al., 2015), as well as decreased GLUT1 and MCT1, MCT2, and MCT4 transporters (denoted by dashed outlines). Left, Low energy levels lead to the activation of AMPK and the subsequent upregulation of PGC-1 $\alpha$ and activation of TXNIP, thereby relieving the constitutive degradation of GLUT1. Activated (phosphorylated) AMPK also phosphorylates TCS2, thereby blocking the conversion of Rheb-GDP to Rheb-GTP and preventing the activation of the mTORC1. Sustained activation of AMPK upregulates ACC 1 and ACC2, promoting fatty acid oxidation. Fatty acid oxidation and utilization of $\beta$ HB provides ATP, thereby blocking AMPK activation. When not active, AMPK no longer blocks mTORC1 activity, allowing the activation of p7056K, the phosphorylation of $\$ 6$, and the subsequent translation of proteins such as MCT2. TXNIP, Thioredoxin-interacting protein; TCS2, tuberous sclerosis complex 2; ACC, acetyl-CoA carboxylase.

$\mathrm{Nrf2}$, the transcription factor that binds to the antioxidant response element to promote expression of genes such as hemeoxygenase-1 (HO-1). There was evidence of translocation of Nrf2 to the nucleus in the D2 ketogenic mouse retina, but not control mouse retina [Fig. $8 A$ (quantification in Fig. $8 F$ ), $t_{(22)}=19.56,{ }^{* *} p=$ $0.0001]$. We confirmed antioxidant response by immunolabeling for $\mathrm{HO}-1$ in retina and $\mathrm{ON}$ (Fig. $8 \mathrm{~B}$ ). There was slightly higher $\mathrm{HO}-1$ immunolabeling in retina and $\mathrm{ON}$ from the ketogenic mice compared with those $\mathrm{D} 2$ mice on the control diet [Fig. $8 \mathrm{G}$, quantification $\left(t_{(22)}=18.65,{ }^{* * *} p=0.0001\right), \boldsymbol{H}$, quantification $\left(t_{(22)}=\right.$ $\left.\left.11.38,{ }^{* *} p=0.0001\right)\right]$.

Astrocytes underwent no change in glycogen levels in the ketogenic ON compared with control diet (compare Fig. 5-1 available at https://doi.org/10.1523/JNEUROSCI.3652-17.2018.f5-1, Fig. $1 A$ ), indicating that the $\mathrm{KD}$ did not impact glycogen stores. Analysis of ON mRNA showed significant decreases in Gfap in the ketogenic mice compared with control, while there was no change in GS (Fig. 5-1 available at https://doi.org/10.1523/JNEUROSCI. 3652-17.2018.f5-1). Since astrocyte volume increases during glucose deprivation while gap-junction coupling decreases (Lee et al., 2016), we measured astrocyte surface area in optic nerve cross sections, finding significantly decreased astrocyte area in the ketogenic versus control groups [Fig. $8 C\left(t_{(12)}=4.983\right.$, ${ }^{* *} p=$ $0.003), D]$, corroborating the decrease in hypertrophy anticipated with lower Gfap mRNA.

BDNF has been shown to be significantly decreased in disorders of energy metabolism such as obesity, hyperglycemia, and insulin desensitivity (Nakagawa et al., 2000; Krabbe et al., 2007), but also neurodegenerative disorders such as Huntington's disease (Zuccato et al., 2001). Restoration of BDNF levels can regulate energy balance (Nakagawa et al., 2002) and slow neurodegenerative disease progression (Duan et al., 2003). BDNF is also necessary for RGC survival (Mansour-Robaey et al., 1994), so we evaluated BDNF protein in retina and ON. BDNF immunolabeling showed significant increases in the ganglion cell layer of retina and in the $\mathrm{ON}$ of KD-fed mice [Fig. $8 E$ (quantification in $I ; t_{(22)}=13.93,{ }^{* *} p=$ $\left.0.0001), J\left(t_{(22)}=18.01,{ }^{* * *} p=0.0001\right)\right]$.

Figure 9 shows a schematic of the substrate transporters involved in the normal and glaucomatous metabolically stressed optic nerve, and the intracellular pathways involved in resolution of energy compromise by the KD.

\section{Discussion}

We investigated the metabolic vulnerability that precedes axon degeneration in the D2 model of glaucoma by examining substrate access and manipulating metabolism. The data presented here support the hypothesis that limited energy substrate compromises axon function in the glaucomatous ON. By 6 months of age in the $\mathrm{D} 2 \mathrm{ON}$, and 4 weeks after bead injection, activation of the primary cellular energy sensor, AMPK, was observed. Phosphorylated AMPK works to restore energy balance by inhibiting ATP-consuming processes in the cells and axons of the ON, including upregulating glucose transporters and inhibiting glycogen synthase to reduce storage of glucose (Hardie, 2013). Tellingly, we observed significantly decreased glycogen levels at 6 and 10 months in the D2 ONs, as well as significant upregulation of 
the axonal glucose transporter GLUT3 mRNA. However, pAMPK is even more upregulated at 10 months than at 6 months in the D2 ONs, indicating that any attempt to restore ATP levels was unsuccessful at 6 months, giving way to sustained activation. The failure to restore ATP is corroborated by the significantly decreased L-lactate and creatine kinase activity observed at 10 months in the D2 ON. Sustained AMPK activation defers glucose synthesis concomitant with a promotion of $\beta$-oxidation, the use of fatty acids as a fuel source. It was into this environment, primed to make use of fatty acids, that we introduced the KD. The KD leads to the breakdown of fatty acids in the liver and the production of ketone bodies. Fatty acids can enter the CNS and may be metabolized to ketone bodies by astrocytes (Guzmán and Blázquez, 2004); however, retinal neurons have also been shown to use fatty acids directly (Joyal et al., 2016; Pearsall et al., 2017).

Ketone bodies enter astrocytes, neurons, and oligodendrocytes through MCTs and are converted to acetyl-CoA in the mitochondria (Gano et al., 2014). Though there was a significant downregulation of MCT1, MCT2, and MCT4 at 10 months in the D2 ON, the transporters were not absent. As the available ketone body substrates grew, both MCT1 and MCT2 were upregulated in ONs of D2 mice on the KD. MCT upregulation occurs in the CNS with KD (Leino et al., 2001) or high-fat diet (Pierre et al., 2007), and in response to ketone bodies or $\beta$-hydroxybutyrate (Halestrap and Meredith, 2004), demonstrating a dynamic response to changing the metabolic substrate. We posit that the initial MCT downregulation in 10-month-old D2 ONs was in response to scarcity of energy substrate; L-lactate levels and astrocyte GLUTs were significantly decreased. Monocarboxylate transporter protein and mRNA levels closely follow lactate levels, suggesting that lactate can regulate MCT expression (Takimoto and Hamada, 2014). MCTs are regulated at the level of translation with signaling through the PI3K-AKT-mTOR-p70S6K pathway (Chenal et al., 2008). We showed significant activity of AKT and upregulation of p70S6K protein, downstream of mTOR, with KD. Both mTOR and pAMPK can increase PGC- $1 \alpha$; these increases can lead to the upregulation of MCT1 and its partner protein basigin, with a resultant $20 \%$ increase in lactate transport (Benton et al., 2008).

What initiated the energy crisis in the D2 ON? Astrocytes are highly glycolytic cells, releasing L-lactate as a byproduct of glycolysis. The $\beta$-regulatory subunit of AMPK has a glycogen-binding domain (Garcia and Shaw, 2017), allowing it to behave as a glycogen sensor (McBride et al., 2009). The AMPK-induced inhibition of glycogen synthase negatively impacted astrocyte glycogen levels at 6 and 10 months in D2 ONs. This should have prompted the upregulation of GLUT1 in the astrocytes. However, this did not occur. There are at least two potential explanations. For one, GLUTs are regulated by local metabolic demand and become upregulated with neural activity (Ferreira et al., 2011), suggesting that their decline may additionally be the outcome of decreased activity in the ON. There is evidence for declines in the physiological activity in the D2 as measured by visual evoked potential as early as 7 months of age (Domenici et al., 2014), as well as declines in compound action potential evoked in isolated 6-month-old D2 ONs (Baltan et al., 2010). A second possibility for the failure of GLUT1 upregulation is limited metabolic support among astrocytes in optic nerve head $(\mathrm{ONH})$ and $\mathrm{ONs}$. Specialized astrocytes of the optic nerve head glia lamina ("fortified astrocytes") undergo degeneration with extended exposure to high IOP (Li et al., 2015). $\mathrm{ONH}$ astrocytes are electrically and metabolically coupled through a gap-junction-mediated syncytium that is disrupted when exposed to high pressure (Malone et al., 2007). Human optic nerve head showed immunolabeling for connexin-43, a major gap junction protein in astrocytes, from the lamina cribosa through to the myelinated ON (Kerr et al., 2011). However, astrocytes lose their gap-junction coupling when deprived of glucose (Lee et al., 2016). The loss of coupling would isolate portions of the astrocyte syncytium, preventing the management of the metabolic, $\mathrm{Ca}^{2+}$, and structural crisis that occurs when astrocytes exposed to chronic IOP increase release their connections with the pial wall (Sun et al., 2010; Dai et al., 2012) before degeneration.

The impact of energy crisis in the $\mathrm{D} 2 \mathrm{ON}$ that begins upon AMPK activation is a vulnerability to oxygen-glucose deprivation and a loss of compound action potential propagation (Baltan et al., 2010), also evident by 6 months of age. D2 RGC axons with anterograde transport deficit nevertheless preserve their connections in the superior colliculus until 13 months of age (Crish et al., 2010; Dengler-Crish et al., 2014), although synaptic changes at 9-11 months include significantly decreased bouton and mitochondrial volume, and the loss and shrinkage of synaptic active zones (Smith et al., 2016). The KD maintained electrical activity in the superior colliculus, possibly by regulation of membrane excitability as observed in other contexts (Paoli et al., 2013). D2 mice at 10 months of age show significantly decreased N1 and P1 amplitude with flash visual evoked potential (Sullivan et al., 2011). In contrast to visual evoked potential changes, we observed increased latency to onset of spike activity in the superior colliculus with the KD. Latency changes are often ascribed to changes in myelination. Our electron microscopic analysis of $\mathrm{ON}$ also did not show evidence of demyelination, and the study by Baltan et al. (2010) showed that blocking $\mathrm{K}^{+}$channels with 4-aminopyridine in D2 ONs did not affect the compound action potential, indicating that demyelination did not occur by 10 months in the D2 ON (Baltan et al., 2010). The other possible source of decreased latency could be alterations in the bipolar-toRGC synapse, of which there is evidence for significant overall decrease in excitatory synapses concomitant with alteration in the receptive field size, dendritic arborization, and complexity of OFF-transient RGCs with acute IOP increase (Della Santina et al., 2013; El-Danaf and Huberman, 2015; Ou et al., 2016).

A proteomic study of retinas from human ocular hypertension patients observed significant changes in energy production and mitochondrial proteins, including $\mathrm{p} 70 \mathrm{~S} 6 \mathrm{~K}$ and $\mathrm{mTOR}$ pathways (Yang et al., 2015). We found evidence of autophagy upregulation in the D2 ON (Coughlin et al., 2015; Kleesattel et al., 2015) with timing that matches our current observation of significant AMPK activation; this follows from the well known promotion of autophagy through AMPK activation of ULK1 (Unc-51-like autophagy activating kinase 1; Egan et al., 2011) and its inhibition of mTORC1. High levels of AKT in the ketogenic ON were accompanied by high levels of p70S6K; AKT works through mTOR to increase p70S6K activation to promote anabolic processes that consume ATP (Manning and Toker, 2017). BDNF can induce mTOR and downstream p70S6K activation (Ishizuka et al., 2013). We found increased BDNF and p70S6K activation with $\mathrm{KD}$, as well as decreased AMPK activation. BDNF can be induced in cortical neurons by $\beta \mathrm{HB}$ (Marosi et al., 2016), a ketone body we observed to be significantly increased in blood plasma and the retinas of KD-fed mice. In a mouse model of normal tension glaucoma, caloric restriction through everyother-day-fasting led to significant upregulation of $\beta \mathrm{HB}$ levels in the retina and improved RGC survival and function concomitant with increased Bdnf, catalase, and bFGF mRNA (Guo et al., 2016). The BDNF induction and downstream pathway activation we observed is consistent with $\beta \mathrm{HB}$ direct action. 
Increased PGC- $1 \alpha$ protein and mRNA with KD were accompanied by significantly more mitochondria in the ON axons and localization of PGC- $1 \alpha$ protein to the nerve fiber layer and astrocytes within the ON. Astrocytes take up $30 \%$ of the volume of the $\mathrm{ON}$ and possess the majority of the mitochondria (Perge et al., 2009), so it is likely that astrocytes comprise a major contribution to the observed PGC- $1 \alpha$ upregulation. One target of PGC- $1 \alpha$, uncoupling protein $\mathrm{UCP} 2$, had significantly lower retina and $\mathrm{ON}$ expression with KD. Mitochondrial uncoupling can be the result of an overabundance of free fatty acid, which can lead to metabolic inefficiency with a KD (Veech, 2004). This does not appear to be the case in the retinas and ONs of the D2 mice, although translational regulation of UCP2 has shown that the mRNA and protein levels do not coincide (Pecqueur et al., 2001), indicating that lower mRNA levels could nevertheless be accompanied by UCP2 induction. Alternatively, the lack of uncoupling could indicate the $\mathrm{ON}$ primarily obtained its fuel from $\beta \mathrm{HB}$ rather than fatty acids, as $\beta \mathrm{HB}$ does not uncouple mitochondria at concentrations that increase oxygen consumption (Tieu et al., 2003).

Unsurprisingly with a diet that promotes respiration, we observed signs of antioxidant response in the ketogenic retina through increases in RGC nuclear immunofluorescence for Nrf2 transcription factor and SOD2. Strong HO-1 immunolabeling accompanied the Nrf2 in retinas and ONs of both control diet and ketogenic mice, indicating the antioxidant response in both groups.

Ketogenic diets have been used to limit neurodegeneration (Kashiwaya et al., 2000). Some KD-induced improvements in Alzheimer's disease models are limited to motor function (Beckett et al., 2013; Brownlow et al., 2013), while others demonstrate improved cognition (Krikorian et al., 2012) and decreased pathology (Yin et al., 2016). In a model of ALS, KD increased motor neuron number and promoted longer survival times (Zhao et al., 2006). Explorations of the mechanisms of KD protection often cite improvement of mitochondrial metabolic efficiency (Veech, 2004; Bough et al., 2006) or normalization of metabolism (Stafstrom and Rho, 2012). Mitochondrial perturbation in one cell or tissue can dictate mitochondrial stress response in another (Durieux et al., 2011). Neither Alzheimer's disease nor ALS is cell autonomous (Nagai et al., 2007; Hertz et al., 2015), and, given the energy management in the CNS at the level of metabolic unit (axon, astrocyte, and blood vessel), it is worthwhile to consider a noncell-autonomous mechanism of neuroprotection with the KD. Glial proliferation, as is evident in the glaucomatous optic nerve (Son et al., 2010), would provide the means for higher production of ketone bodies through a KD. The KD also changes the metabolic profile of glial cells, as we observed with increased PGC- $1 \alpha$ expression and SDH and COX activity. These outcomes likely enable greater substrate availability for axons, and they would also contribute to the maintenance of the glutamate-glutamine cycle, the critical exchange between astrocytes and neurons that manages extracellular glutamate levels.

The protection of RGC cell bodies and axons in this study occurred with a 2 month dietary intervention that was applied when physiological and some structural changes in the RGCs had already transpired, and resulted in a resolution of metabolic insufficiency. Future investigation will resolve whether the improvements are temporary or dependent on key aspects of the diet, or the known effects of $\beta \mathrm{HB}$ were necessary or sufficient for the observed effect of the diet in this model.

\section{References}

Anderson MG, Smith RS, Hawes NL, Zabaleta A, Chang B, Wiggs JL, John SW (2002) Mutations in genes encoding melanosomal proteins cause pig- mentary glaucoma in DBA/2J mice. Nat Genet 30:81-85. CrossRef Medline

Anson RM, Guo Z, de Cabo R, Iyun T, Rios M, Hagepanos A, Ingram DK, Lane MA, Mattson MP (2003) Intermittent fasting dissociates beneficial effects of dietary restriction on glucose metabolism and neuronal resistance to injury from calorie intake. Proc Natl Acad Sci U S A 100:62166220. CrossRef Medline

Araki T, Sasaki Y, Milbrandt J (2004) Increased nuclear NAD biosynthesis and SIRT1 activation prevent axonal degeneration. Science 305:10101013. CrossRef Medline

Baltan S, Inman DM, Danilov CA, Morrison RS, Calkins DJ, Horner PJ (2010) Metabolic vulnerability disposes retinal ganglion cell axons to dysfunction in a model of glaucomatous degeneration. J Neurosci 30: 5644-5652. CrossRef Medline

Beckett TL, Studzinski CM, Keller JN, Paul Murphy M, Niedowicz DM (2013) A ketogenic diet improves motor performance but does not affect $\beta$-amyloid levels in a mouse model of Alzheimer's disease. Brain Res 1505:61-67. CrossRef Medline

Benton CR, Yoshida Y, Lally J, Han XX, Hatta H, Bonen A (2008) PGClalpha increases skeletal muscle lactate uptake by increasing the expression of MCT1 but not MCT2 or MCT4. Physiol Genomics 35:45-54. CrossRef Medline

Bosco A, Breen KT, Anderson SR, Steele MR, Calkins DJ, Vetter ML (2016) Glial coverage in the optic nerve expands in proportion to optic axon loss in chronic mouse glaucoma. Exp Eye Res 150:34-43. CrossRef Medline

Bough KJ, Wetherington J, Hassel B, Pare JF, Gawryluk JW, Greene JG, Shaw R, Smith Y, Geiger JD, Dingledine RJ (2006) Mitochondrial biogenesis in the anticonvulsant mechanism of the ketogenic diet. Ann Neurol 60: 223-235. CrossRef Medline

Bouzier-Sore AK, Voisin P, Bouchaud V, Bezancon E, Franconi JM, Pellerin L (2006) Competition between glucose and lactate as oxidative energy substrates in both neurons and astrocytes: a comparative NMR study. Eur J Neurosci 24:1687-1694. CrossRef Medline

Brownlow ML, Benner L, D’Agostino D, Gordon MN, Morgan D (2013) Ketogenic diet improves motor performance but not cognition in two mouse models of Alzheimer's pathology. PLoS One 8:e75713. CrossRef Medline

Buckingham BP, Inman DM, Lambert W, Oglesby E, Calkins DJ, Steele MR, Vetter ML, Marsh-Armstrong N, Horner PJ (2008) Progressive ganglion cell degeneration precedes neuronal loss in a mouse model of glaucoma. J Neurosci 28:2735-2744. CrossRef Medline

Chenal J, Pierre K, Pellerin L (2008) Insulin and IGF-1 enhance the expression of the neuronal monocarboxylate transporter MCT2 by translational activation via stimulation of the phosphoinositide 3-kinase-akt-mammalian target of rapamycin pathway. Eur J Neurosci 27:53-65. CrossRef Medline

Coughlin L, Morrison RS, Horner PJ, Inman DM (2015) Mitochondrial morphology differences and mitophagy deficit in murine glaucomatous optic nerve. Invest Ophthalmol Vis Sci 56:1437-1446. CrossRef Medline

Crish SD, Sappington RM, Inman DM, Horner PJ, Calkins DJ (2010) Distal axonopathy with structural persistence in glaucomatous neurodegeneration. Proc Natl Acad Sci U S A 107:5196-5201. CrossRef Medline

Dai C, Khaw PT, Yin ZQ, Li D, Raisman G, Li Y (2012) Structural basis of glaucoma: the fortified astrocytes of the optic nerve head are the target of raised intraocular pressure. Glia 60:13-28. CrossRef Medline

Della Santina L, Inman DM, Lupien CB, Horner PJ, Wong RO (2013) Differential progression of structural and functional alterations in distinct retinal ganglion cell types in a mouse model of glaucoma. J Neurosci 33:17444-17457. CrossRef Medline

Dengler-Crish CM, Smith MA, Inman DM, Young JW, Wilson GN, Crish SD (2014) Anterograde transport blockade precedes deficits in retrograde transport in the visual projection of the DBA / 2J mouse model of glaucoma. Front Neurosci 8:290. CrossRef Medline

DeVivo DC, Leckie MP, Ferrendelli JS, McDougal DB Jr (1978) Chronic ketosis and cerebral metabolism. Ann Neurol 3:331-337. CrossRef Medline

Dhahbi JM, Mote PL, Fahy GM, Spindler SR (2005) Identification of potential caloric restriction mimetics by microarray profiling. Physiol Genomics 23:343-350. CrossRef Medline

Ding C, Wang P, Tian N (2011) Effect of general anesthetics on IOP in elevated IOP mouse model. Exp Eye Res 92:512-520. CrossRef Medline

Domenici L, Origlia N, Falsini B, Cerri E, Barloscio D, Fabiani C, Sans M, Giovannini L (2014) Rescue of retinal function by BDNF in a mouse model of glaucoma. PLoS One 9:1-25. CrossRef Medline 
Duan W, Guo Z, Jiang H, Ware M, Li XJ, Mattson MP (2003) Dietary restriction normalizes glucose metabolism and BDNF levels, slows disease progression, and increases survival in huntingtin mutant mice. Proc Natl Acad Sci U S A 100:2911-2916. CrossRef Medline

Durieux J, Wolff S, Dillin A (2011) The cell-non-autonomous nature of electron transport chain-mediated longevity. Cell 144:79-91. CrossRef Medline

Egan DF, Shackelford DB, Mihaylova MM, Gelino S, Kohnz RA, Mair W, Vasquez DS, Joshi A, Gwinn DM, Taylor R, Asara JM, Fitzpatrick J, Dillin A, Viollet B, Kundu M, Hansen M, Shaw RJ (2011) Phosphorylation of ULK1 (hATG1) by AMP-activated protein kinase connects energy sensing to mitophagy. Science 331:456-461. CrossRef Medline

El-Danaf RN, Huberman AD (2015) Characteristic patterns of dendritic remodeling in early-stage glaucoma: evidence from genetically identified retinal ganglion cell types. J Neurosci 35:2329-2343. CrossRef Medline

Ellis EM, Gauvain G, Sivyer B, Murphy GJ (2016) Shared and distinct retinal input to the mouse superior colliculus and dorsal lateral geniculate nucleus. J Neurophysiol 116:602-610. CrossRef Medline

Ferreira JM, Burnett AL, Rameau GA (2011) Activity-dependent regulation of surface glucose transporter-3. J Neurosci 31:1991-1999. CrossRef Medline

Gano LB, Patel M, Rho JM (2014) Ketogenic diets, mitochondria, and neurological diseases. J Lipid Res 55:2211-2228. CrossRef Medline

Garcia D, Shaw RJ (2017) AMPK: mechanisms of cellular energy sensing and restoration of metabolic balance. Mol Cell 66:789-800. CrossRef Medline

Gerdts J, Brace EJ, Sasaki Y, DiAntonio A, Milbrandt J (2015) SARM1 activation triggers axon degeneration locally via NAD + destruction. Science 348:453-457. CrossRef Medline

Guo X, Dason ES, Zanon-Moreno V, Jiang Q, Nahirnyj A, Chan D, Flanagan JG, Sivak JM (2014) PGC- $1 \alpha$ signaling coordinates susceptibility to metabolic and oxidative injury in the inner retina. Am J Pathol 184:10171029. CrossRef Medline

Guo X, Kimura A, Azuchi Y, Akiyama G, Noro T, Harada C, Namekata K, Harada T (2016) Caloric restriction promotes cell survival in a mouse model of normal tension glaucoma. Sci Rep 6:33950. CrossRef Medline

Guzmán M, Blázquez C (2004) Ketone body synthesis in the brain: possible neuroprotective effects. Prostaglandins Leukot Essent Fatty Acids 70:287292. CrossRef Medline

Halestrap AP, Meredith D (2004) The SLC16 gene family-from monocarboxylate transporters (MCTs) to aromatic amino acid transporters and beyond. Pflugers Arch 447:619-628. CrossRef Medline

Hardie DG (2013) AMPK: a target for drugs and natural products with effects on both diabetes and cancer. Diabetes 62:2164-2172. CrossRef Medline

Henderson ST, Vogel JL, Barr LJ, Garvin F, Jones JJ, Costantini LC (2009) Study of the ketogenic agent AC-1202 in mild to moderate Alzheimer's disease: a randomized, double-blind, placebo-controlled, multicenter trial. Nutr Metab (Lond) 6:31. CrossRef Medline

Hertz L, Chen Y, Waagepetersen HS (2015) Effects of ketone bodies in Alzheimer's disease in relation to neural hypometabolism, $\beta$-amyloid toxicity, and astrocyte function. J Neurochem 134:7-20. CrossRef Medline

Hou Z, He L, Qi RZ (2007) Regulation of S6 kinase 1 activation by phosphorylation at ser-411. J Biol Chem 282:6922-6928. CrossRef Medline

Howell GR, Libby RT, Jakobs TC, Smith RS, Phalan FC, Barter JW, Barbay JM, Marchant JK, Mahesh N, Porciatti V, Whitmore AV, Masland RH, John SW (2007) Axons of retinal ganglion cells are insulted in the optic nerve early in DBA/2J glaucoma. J Cell Biol 179:1523-1537. CrossRef Medline

Ingram DK, Zhu M, Mamczarz J, Zou S, Lane MA, Roth GS, deCabo R (2006) Calorie restriction mimetics: an emerging research field. Aging Cell 5:97-108. CrossRef Medline

Ishizuka Y, Kakiya N, Witters LA, Oshiro N, Shirao T, Nawa H, Takei N (2013) AMP-activated protein kinase counteracts brain-derived neurotrophic factor-induced mammalian target of rapamycin complex 1 signaling in neurons. J Neurochem 127:66-77. CrossRef Medline

Joyal JS, Sun Y, Gantner ML, Shao Z, Evans LP, Saba N, Fredrick T, Burnim S, Kim JS, Patel G, Juan AM, Hurst CG, Hatton CJ, Cui Z, Pierce KA, Bherer P, Aguilar E, Powner MB, Vevis K, Boisvert M, et al. (2016) Retinal lipid and glucose metabolism dictates angiogenesis through the lipid sensor Ffar1. Nat Med 22:439-445. CrossRef Medline

Ju WK, Kim KY, Lindsey JD, Angert M, Duong-Polk KX, Scott RT, Kim JJ, Kukhmazov I, Ellisman MH, Perkins GA, Weinreb RN (2008) Intraocular pressure elevation induces mitochondrial fission and triggers OPA1 release in glaucomatous optic nerve. Invest Ophthalmol Vis Sci 49:49034911. CrossRef Medline

Kaneda K, Isa T (2013) GABAergic mechanisms for shaping transient visual responses in the mouse superior colliculus. Neuroscience 235:129-140. CrossRef Medline

Kashiwaya Y, Takeshima T, Mori N, Nakashima K, Clarke K, Veech RL (2000) D-B-hydroxybutyrate protects neurons in models of Alzheimer's and Parkinson's disease. Proc Natl Acad Sci U S A 97:5440-5444. CrossRef Medline

Kerr NM, Johnson CS, Green CR, Danesh-Meyer HV (2011) Gap junction protein connexin43 (GJA1) in the human glaucomatous optic nerve head and retina. J Clin Neurosci 18:102-108. CrossRef Medline

Kleesattel D, Crish SD, Inman DM (2015) Decreased energy capacity and increased autophagic activity in optic nerve axons with defective anterograde transport. Investig Ophthalmol Vis Sci 56:8215-8227. CrossRef Medline

Kowald A, Kirkwood TB (2000) Accumulation of defective mitochondria through delayed degradation of damaged organelles and its possible role in the ageing of post-mitotic and dividing cells. J Theor Biol 202:145-160. CrossRef Medline

Krabbe KS, Nielsen AR, Krogh-Madsen R, Plomgaard P, Rasmussen P, Erikstrup C, Fischer CP, Lindegaard B, Petersen AM, Taudorf S, Secher NH, Pilegaard H, Bruunsgaard H, Pedersen BK (2007) Brain-derived neurotrophic factor (BDNF) and type 2 diabetes. Diabetologia 50:431-438. CrossRef Medline

Krikorian R, Shidler MD, Dangelo K, Couch SC, Benoit SC, Clegg DJ (2012) Dietary ketosis enhances memory in mild cognitive impairment. Neurobiol Aging 33:425.e19-27. CrossRef Medline

Lee CY, Dallérac G, Ezan P, Anderova M, Rouach N (2016) Glucose tightly controls morphological and functional properties of astrocytes. Front Aging Neurosci 8:82. CrossRef Medline

Lee Y, Morrison BM, Li Y, Lengacher S, Farah MH, Hoffman PN, Liu Y, Tsingalia A, Jin L, Zhang PW, Pellerin L, Magistretti PJ, Rothstein JD (2012) Oligodendroglia metabolically support axons and contribute to neurodegeneration. Nature 487:443-448. CrossRef Medline

Leino RL, Gerhart DZ, Duelli R, Enerson BE, Drewes LR (2001) Dietinduced ketosis increases monocarboxylate transporter (MCT1) levels in rat brain. Neurochem Int 38:519-527. CrossRef Medline

Li Y, Li D, Ying X, Khaw PT, Raisman G (2015) An energy theory of glaucoma. Glia 63:1537-1552. CrossRef Medline

Lin HC, Stein JD, Nan B, Childers D, Newman-Casey PA, Thompson DA, Richards JE (2015) Association of geroprotective effects of metformin and risk of open-angle glaucoma in persons with diabetes mellitus. JAMA Ophthalmol 133:915-923. CrossRef Medline

Maalouf M, Rho JM, Mattson MP (2009) The neuroprotective properties of calorie restriction, the ketogenic diet, and ketone bodies. Brain Res Rev 59:293-315. CrossRef Medline

Malone P, Miao H, Parker A, Juarez S, Hernandez MR (2007) Pressure induces loss of gap junction communication and redistribution of connexin 43 in astrocytes. Glia 55:1085-1098. CrossRef Medline

Manning BD, Toker A (2017) AKT/PKB signaling: navigating the network. Cell 169:381-405. CrossRef Medline

Mansour-Robaey S, Clarke DB, Wang YC, Bray GM, Aguayo AJ (1994) Effects of ocular injury and administration of brain-derived neurotrophic factor on survival and regrowth of axotomized retinal ganglion cells. Proc Natl Acad Sci U S A 91:1632-1636. CrossRef Medline

Marosi K, Kim SW, Moehl K, Scheibye-Knudsen M, Cheng A, Cutler R, Camandola S, Mattson MP (2016) 3-Hydroxybutyrate regulates energy metabolism and induces BDNF expression in cerebral cortical neurons. J Neurochem 139:769-781. CrossRef Medline

McBride A, Ghilagaber S, Nikolaev A, Hardie DG (2009) The glycogenbinding domain on the AMPK beta subunit allows the kinase to act as a glycogen sensor. Cell Metab 9:23-34. CrossRef Medline

Nagai M, Re DB, Nagata T, Chalazonitis A, Jessell TM, Wichterle H, Przedborski S (2007) Astrocytes expressing ALS-linked mutated SOD1 release factors selectively toxic to motor neurons. Nat Neurosci 10:615-622. CrossRef Medline

Nakagawa T, Tsuchida A, Itakura Y, Nonomura T, Ono M, Hirota F, Inoue T, Nakayama C, Taiji M, Noguchi H (2000) Brain-derived neurotrophic factor regulates glucose metabolism by modulating energy balance in diabetic mice. Diabetes 49:436-444. CrossRef Medline

Nakagawa T, Ono-Kishino M, Sugaru E, Yamanaka M, Taiji M, Noguchi H (2002) Brain-derived neurotrophic factor (BDNF) regulates glucose and 
energy metabolism in diabetic mice. Diabetes Metab Res Rev 18:185-191. CrossRef Medline

Ou Y, Jo RE, Ullian EM, Wong RO, Della Santina L (2016) Selective vulnerability of specific retinal ganglion cell types and synapses after transient ocular hypertension. J Neurosci 36:9240-9252. CrossRef Medline

Ozawa T (1995) Mechanism of somatic mitochondrial DNA mutations associated with age and diseases. Biochim Biophys Acta 1271:177-189. CrossRef Medline

Paoli A, Rubini A, Volek JS, Grimaldi KA (2013) Beyond weight loss: a review of the therapeutic uses of very-low-carbohydrate (ketogenic) diets. Eur J Clin Nutr 67:789-796. CrossRef Medline

Pearsall EA, Cheng R, Zhou K, Takahashi Y, Matlock HG, Vadvalkar SS, Shin Y, Fredrick TW, Gantner ML, Meng S, Fu Z, Gong Y, Kinter M, Humphries KM, Szweda LI, Smith LEH, Ma JX (2017) PPAR $\alpha$ is essential for retinal lipid metabolism and neuronal survival. BMC Biol 15:113. CrossRef Medline

Pecqueur C, Alves-Guerra MC, Gelly C, Lévi-Meyrueis C, Couplan E, Collins S, Ricquier D, Bouillaud F, Miroux B (2001) Uncoupling protein 2, in vivo distribution, induction upon oxidative stress, and evidence for translational regulation. J Biol Chem 276:8705-8712. CrossRef Medline

Perge JA, Koch K, Miller R, Sterling P, Balasubramanian V (2009) How the optic nerve allocates space, energy capacity, and information. J Neurosci 29:7917-7928. CrossRef Medline

Pierre K, Magistretti PJ, Pellerin L (2002) MCT2 is a major neuronal monocarboxylate transporter in the adult mouse brain. J Cereb Blood Flow Metab 22:586-595. CrossRef Medline

Pierre K, Parent A, Jayet PY, Halestrap AP, Scherrer U, Pellerin L (2007) Enhanced expression of three monocarboxylate transporter isoforms in the brain of obese mice. J Physiol 583:469-486. CrossRef Medline

Rafiki A, Boulland JL, Halestrap AP, Ottersen OP, Bergersen L (2003) Highly differential expression of the monocarboxylate transporters MCT2 and MCT4 in the developing rat brain. Neuroscience 122:677-688. CrossRef Medline

Rahman M, Muhammad S, Khan MA, Chen H, Ridder DA, Müller-Fielitz H, Pokorná B, Vollbrandt T, Stölting I, Nadrowitz R, Okun JG, Offermanns S, Schwaninger M (2014) The $\beta$-hydroxybutyrate receptor HCA2 activates a neuroprotective subset of macrophages. Nat Commun 5:3944. CrossRef Medline

Saab AS, Tzvetavona ID, Trevisiol A, Baltan S, Dibaj P, Kusch K, Möbius W, Goetze B, Jahn HM, Huang W, Steffens H, Schomburg ED, PérezSamartín A, Pérez-Cerdá F, Bakhtiari D, Matute C, Löwel S, Griesinger C, Hirrlinger J, Kirchhoff F, et al. (2016) Oligodendroglial NMDA receptors regulate glucose import and axonal energy metabolism. Neuron 91: 119-132. CrossRef Medline

Sappington RM, Carlson BJ, Crish SD, Calkins DJ (2010) The microbead occlusion model: a paradigm for induced ocular hypertension in rats and mice. Invest Ophthalmol Vis Sci 51:207-216. CrossRef Medline

Sasaki Y, Vohra BP, Lund FE, Milbrandt J (2009) Nicotinamide mononucleotide adenylyl transferase-mediated axonal protection requires enzymatic activity but not increased levels of neuronal nicotinamide adenine dinucleotide. J Neurosci 29:5525-5535. CrossRef Medline

Schindelin J, Arganda-Carreras I, Frise E, Kaynig V, Longair M, Pietzsch T, Preibisch S, Rueden C, Saalfeld S, Schmid B, Tinevez JY, White DJ, Hartenstein V, Eliceiri K, Tomancak P, Cardona A (2012) Fiji: an opensource platform for biological-image analysis. Nat Methods 9:676-682. CrossRef Medline

Shen H, Hyrc KL, Goldberg MP (2013) Maintaining energy homeostasis is an essential component of Wld(S)-mediated axon protection. Neurobiol Dis 59:69-79. CrossRef Medline

Shimazu T, Hirschey MD, Newman J, He W, Shirakawa K, Le Moan N, Grueter CA, Lim H, Saunders LR, Stevens RD, Newgard CB, Farese RV Jr, de Cabo R, Ulrich S, Akassoglou K, Verdin E (2013) Suppression of oxidative stress by $\beta$-hydroxybutyrate, an endogenous histone deacetylase inhibitor. Science 339:211-214. CrossRef Medline

Simpson IA, Carruthers A, Vannucci SJ (2007) Supply and demand in cerebral energy metabolism: the role of nutrient transpoters. J Cereb Blood Flow Metab 27:1766-1791. CrossRef Medline

Smith MA, Xia CZ, Dengler-Crish CM, Fening KM, Inman DM, Schofield BR, Crish SD (2016) Persistence of intact retinal ganglion cell terminals after axonal transport loss in the DBA/2J mouse model of glaucoma. J Comp Neurol 524:3503-3517. CrossRef Medline

Son JL, Soto I, Oglesby E, Lopez-Roca T, Pease ME, Quigley HA, MarshArmstrong N (2010) Glaucomatous optic nerve injury involves early astrocyte reactivity and late oligodendrocyte loss. Glia 58:780-789. CrossRef Medline

Song BJ, Aiello LP, Pasquale LR (2016) Presence and risk factors for glaucoma patients in diabetes. Curr Diab Rep 16:124. CrossRef Medline

Stafstrom CE, Rho JM (2012) The ketogenic diet as a treatment paradigm for diverse neurological disorders. Front Pharmacol 3:59. CrossRef Medline

Sullivan PG, Rippy NA, Dorenbos K, Concepcion RC, Agarwal AK, Rho JM (2004) The ketogenic diet increases mitochondrial uncoupling protein levels and activity. Ann Neurol 55:576-580. CrossRef Medline

Sullivan TA, Geisert EE, Hines-Beard J, Rex TS (2011) Systemic adenoassociated virus-mediated gene therapy preserves retinal ganglion cells and visual function in DBA/2J glaucomatous mice. Hum Gene Ther 22: 1191-1200. CrossRef Medline

Sun D, Lye-Barthel M, Masland RH, Jakobs TC (2010) Structural remodeling of fibrous astrocytes after axonal injury. J Neurosci 30:14008-14019. CrossRef Medline

Takimoto M, Hamada T (2014) Acute exercise increases brain regionspecific expression of MCT1, MCT2, MCT4, GLUT1, and COX IV proteins. J Appl Physiol 116:1238-1250. CrossRef Medline

Tieu K, Perier C, Caspersen C, Teismann P, Wu DC, Yan SD, Naini A, Vila M, Jackson-Lewis V, Ramasamy R, Przedborski S (2003) D- $\beta$-hydroxybutyrate rescues mitochondrial respiration and mitigates features of parkinson disease. J Clin Invest 112:892-901. CrossRef Medline

Veech RL (2004) The therapeutic implications of ketone bodies: the effects of ketone bodies in pathological conditions: ketosis, ketogenic diet, redox states, insulin resistance, and mitochondrial metabolism. Prostaglandins Leukot Essent Fatty Acids 70:309-319. CrossRef Medline

Viollet B, Guigas B, Sanz Garcia N, Leclerc J, Foretz M, Andreelli F (2012) Cellular and molecular mechanisms of metformin: an overview. Clin Sci 122:253-270. CrossRef Medline

Wang J, Zhai Q, Chen Y, Lin E, Gu W, McBurney MW, He Z (2005) A local mechanism mediates NAD-dependent protection of axon degeneration. J Cell Biol 170:349-355. CrossRef Medline

Williams PA, Harder JM, Foxworth NE, Cochran KE, Philip VM, Porciatti V, Smithies O, John SWM (2017) Vitamin B3 modulates mitochondrial vulnerability and prevents glaucoma in aged mice. Science 760:756-760. CrossRef Medline

Wu Z, Puigserver P, Andersson U, Zhang C, Adelmant G, Mootha V, Troy A, Cinti S, Lowell B, Scarpulla RC, Spiegelman BM (1999) Mechanisms controlling mitochondrial biogenesis and respiration through the thermogenic coactivator PGC-1. Cell 98:115-124. CrossRef Medline

Yang X, Cheng B (2010) Neuroprotective and anti-inflammatory activities of ketogenic diet on MPTP-induced neurotoxicity. J Mol Neurosci 42: 145-153. CrossRef Medline

Yang X, Hondur G, Li M, Cai J, Klein JB, Kuehn MH, Tezel G (2015) Proteomics analysis of molecular risk factors in the ocular hypertensive human retina. Invest Ophthalmol Vis Sci 56:5816-5830. CrossRef Medline

Yin JX, Maalouf M, Han P, Zhao M, Gao M, Dharshaun T, Ryan C, Whitelegge J, Wu J, Eisenberg D, Reiman EM, Schweizer FE, Shi J (2016) Ketones block amyloid entry and improve cognition in an Alzheimer's model. Neurobiol Aging 39:25-37. CrossRef Medline

Zhai RG, Cao Y, Hiesinger PR, Zhou Y, Mehta SQ, Schulze KL, Verstreken P, Bellen HJ (2006) Drosophila NMNAT maintains neural integrity independent of its NAD synthesis activity. PLoS Biol 4:e416. CrossRef Medline

Zhai RG, Zhang F, Hiesinger PR, Cao Y, Haueter CM, Bellen HJ (2008) NAD synthase NMNAT acts as a chaperone to protect against neurodegeneration. Nature 452:887-891. CrossRef Medline

Zhao Z, Lange DJ, Voustianiouk A, MacGrogan D, Ho L, Suh J, Humala N, Thiyagarajan M, Wang J, Pasinetti GM (2006) A ketogenic diet as a potential novel therapeutic intervention in amyotrophic lateral sclerosis. BMC Neurosci 7:29. CrossRef Medline

Zuccato C, Ciammola A, Rigamonti D, Leavitt BR, Goffredo D, Conti L, MacDonald ME, Friedlander RM, Silani V, Hayden MR, Timmusk T, Sipione S, Cattaneo E (2001) Loss of huntingtin-mediated BDNF gene transcription in Huntington's disease. Science 293:493-498. CrossRef Medline 